\section{EMBRYRIDDLE \\ Aeronautical University}

SCHOLARLY COMMONS

\section{International Journal of Aviation,} Aeronautics, and Aerospace

\title{
Autonomous Airliners Anytime Soon?
}

\author{
Samuel M. Vance \\ Oklahoma State University - Main Campus, matt.vance@okstate.edu \\ Evan C. Bird \\ Oklahoma State University, bird.evan.c@gmail.com \\ Daniel J. Tiffin \\ Case-Western Reserve University, daniel.j.tiffın@nasa.gov
}

Follow this and additional works at: https://commons.erau.edu/ijaaa

Part of the Other Operations Research, Systems Engineering and Industrial Engineering Commons, and the Science and Technology Policy Commons

\section{Scholarly Commons Citation}

Vance, S. M., Bird, E. C., \& Tiffin, D. J. (2019). Autonomous Airliners Anytime Soon?. International Journal of Aviation, Aeronautics, and Aerospace, 6(4). https://doi.org/10.15394/ijaaa.2019.1402

This Article is brought to you for free and open access by the Journals at Scholarly Commons. It has been accepted for inclusion in International Journal of Aviation, Aeronautics, and Aerospace by an authorized administrator of Scholarly Commons. For more information, please contact commons@erau.edu. 


\section{Autonomous Airliners Anytime Soon?}

\section{Introduction}

Imagine sometime in the future you are rushing to catch an airline flight after a busy, successful, out-of-town meeting. Apparently being the last one through the gate and down the jet way, you hurriedly enter the aircraft and are greeted by a smiling flight attendant. Glancing into the empty cockpit, you sigh in relief and state, "Well, at least I'm not as late as the pilots!" The flight attendant, now with a cheek-high smile replies, "Oh, we're ready to go...this flight is now totally automated! This should have been mentioned when you booked your ticket..." Standing in astonishment, and momentarily incapacitated by a flurry of thoughts ranging from amazement to fear, you realize a quick decision is in order. Would you do a $180^{\circ}$ turn, refusing to board the aircraft? Would you pause, return the smile, and casually continue to your seat, wondering if a refreshment robot will offer you a coffee? What factors would be important to you in making the decision...to fly or not to fly, on an unmanned, fully autonomous airliner? Is this realistic anytime soon? These questions are the essence of this research.

This research serves primarily as a) an update to the data collected in 2013 and published in Vance (2014) and in Vance \& Malik (2015), and b) to assess the degree and magnitude of change in the public's propensity to fly on autonomous airliners. Longitudinal trending over the last 16 years will also be developed and shown.

From an airline perspective, it would be lucrative to understand if a premium-frequent flyer club membership assessment of the willingness to travel aboard a fully autonomous airliner would be statistically significantly different than assessed from the general (flying) public; however, and very reluctantly, this demographic (premium frequent flyer club membership) is not easily accessible and generally aggressively protected by reputable airlines since these repeat, loyal customers are willing to pay business/first-class fares. Vance's prior research (2014) suggests this target audience would likely be either an early technology adopter or wholesale rejecter of the encroachment of automation supplanting human pilots. Because this demographic was not easily obtainable, this research relies on a generalpopulation survey of adults (simply defined as those age 18 or over).

Autonomy is methodically infusing previously unexpected facets of daily, human life and may ultimately replace any repetitive task currently accomplished by human labor. Starting with factory assembly (post-WWII), autonomy has migrated through our financial purchasing habits from physical groceries to on-line commerce, including Wall-Street investment bidding. Autonomy has experienced a surprisingly fast migration in the medical field, and especially surgery. The trust of machines has infiltrated oceanic shipping, open pit mining, freight/passenger trains, trucking, and is now quickly gaining traction in personal automobiles (Bellamy, 2017; Negroni, 2019; Sigal, 2019), as well as being actively pursued for General Aviation (Sampson, 2018). For an intriguing look at the advancement of autonomy across 
humanity, review the YouTube clip "Humans Need Not Apply" (https://www.youtube.com/watch?v=7Pq-S557XQU).

The last bastion of human-controlled transport to yield to autonomy will likely be airliner travel for the simple reason humans are not yet ready to trust passenger flight to machines (robots). While there are theoretical safety advantages to autonomous airliner travel, and some may argue - except for the handful of pilot hand-flown minutes at the beginning and end of a typical long-haul airliner journey - autonomous airliner travel is practically here already (Bachman, 2018; Rice 2019; Straub, 2018; Witcher, 2018). However, it is not here yet, nor really even close for the following three reasons, a) the reliable acceptance rate of such a notion is still below the $50 \%$ early adopter acceptance rate common in new/entrepreneurial product markets (Britt \& Nelson, 1976), b) there remains a high degree of well-deserved respect for the ability of direct, human-pilot presence and intervention in the safe outcome of any flight, even more so in extremis/emergency situations (Vartabedian, \& Masunaga 2018), and c) the regulatory and cyber-security issues which would be necessary foundations to support autonomous carriage of passengers are understatedly significant and would require a long gestation period to reach acceptable levels of safety, which at the minimum must mirror the current, nearly impeccable, air-carrier-safety levels of developed countries in North America, Europe, and Middle East (Coren, 2019).

This research seeks to assess the trajectory of autonomous-airliner travel and illuminate whether or not specific, associated-trust issues are technologically and psychologically satisfactory to the end-users, the paying passengers. While the formal, academic, research space on the notion of autonomous-airliner travel is lean, the subject has increasingly been informally deliberated in the digital media - and while the autonomous ability may not be so technically distant, it does appear to be a significant, psychological-trust leap for many respondents (Batchelor, 2018; Bostock, 2019; Owens, 2017; Rice, 2019, Shelton, 2018). Graves (2018) corroborates flying airliners safely and routinely is a complicated and delicate balance between the sophistication of the machine (airliner), the operation of the airliners by their professional crews (pilots), and the interaction between the pilots, the airliners themselves, and Air Traffic Control (ATC). This balance would have to be reliably improved upon before the possibility of autonomous-airliner travel would likely make logical and, maybe more of a driving force, economic sense. The continuing discussion this research perpetuates is not intended to denigrate, undermine, or shorten the professions of commercial piloting or air traffic control; rather, it is simply to understand if the genuine acceptance of airliner automation is continuing to advance, and if so, on what foundation or basis is this advancement predicated?

The research questions upon which this study focuses are:

RQ1 - Would a general population assessment of the willingness to travel aboard a fully autonomous airliner be statistically significantly different than the predominantly aviation, science and technology sample taken by the principal investigator in Oct 2013? 
RQ2 - What influence do the selected factors have on the decision to travel on an autonomous airliner?

\section{Literature Review}

How much longer will airline piloting be a profession? Even aerospace giants such as Boeing are pondering this question (CNBC, 2017). Swedish Press (2003) quoted Craig Mundie, the chief engineer of Microsoft as having already made a substantial and very public bet, "passengers will routinely travel in pilotless planes by 2030." Since the dawn of flight, all passenger aircraft have been directly controlled by humans aboard the aircraft. For commercial passenger air travel, it has been an unspoken assumption and comfort to know the person controlling the plane has a vested interest in the flight's success. It is unlikely this will be the case forever. With labor being the second largest expense behind fuel for an airline, according to IATA (2010), dramatic, pilot-staff cuts could result in cheaper fares and higher profits. Given human error has consistently accounted for roughly $80 \%$ of all aircraft accidents (Rankin, 2007), coupled with the possible cost benefits, it is possible to contemplate why humans are still flying airliners. Is this question reasonable?

This research assumes the technological ability for fully autonomous airliners is available (although not yet proven) thus serving as a basis for updating previous research on the propensity of passengers to travel on autonomous airliners. A short, 20 years ago, three crew members was the norm for piloting passenger aircraft (Moskvitch, 2016). Brazilian manufacturer, Embraer, proposed nearly 10 years ago to shed another crewmember, leaving just one (Doyle, 2010). Boeing, Airbus (Bryan, 2018) and the air cargo industry (Reed, 2018) are in active pursuit of reduced crew operations. In an article for Flight Global, Doyle (2010) reports Embraer sees single-pilot capable airliners as a possibility between 2020 and 2025. Luiz Sergio Chiessi is quoted in the Doyle article, "Airlines are not coming to us with the idea - this is more a vision that we have. We believe that it is technically possible, but we don't know if it is going to be accepted by the public and the authorities."

British Aerospace Systems (BAE), however, is going a step further by removing both pilots (Marks, 2014). Hollinger (2016) reported BAE has heavily modified a Jetstream 31 for autonomous testing. The aircraft is designed to be able to avoid weather as well as other aircraft. It can also find a safe place to land in case of an emergency. In controlled airspace, a ground-based operator is required to input air traffic controller's commands. In the future however, it seems reasonable air traffic controllers will not just talk to pilots, but will actually input commands directly into the plane's flight management system (FMS). It is worth noting $B A E$ is not interested in developing an airliner, they strictly work on military projects. According to a BAE representative, "But we would trade out intellectual property into that sort of partnership." DARPA and NASA are both working on separate technologies to increase automation levels in commercial-air transport and decrease the number of pilots onboard from two to one (Markoff, 2015). 
Even if sterile, machine automation is statistically safer, Epley, Heafner, and Waytz's (2014) research to gauge public acceptance of autonomous cars found people felt safer when the car showed some sign of emotion or exhibited other human-like thinking or qualities. Le Tallec, Joulia, and Harel (2013) discussed the idea of remotely operated planes with pilots who communicate with their passengers would increase their trust in the technology.

Communication from a pilot could potentially increase passengers' perceived safety compared to a pilot who simply flew the plane silently. The idea of an intelligent human being watching over them and assuring their safety continues to give passengers comfort (Isidore, 2015; Le Tallec, Joulia, and Harel, 2013). Such research further suggests the issue is not a technical challenge but a matter of human trust as well as public opinion. The use of autonomous cars may also sway public opinion into accepting autonomous passenger flight according to Ridley (2014).

Another recent, Chinese, technological advance could also accelerate the acceptance of autonomous personal travel by air - the development of the Ehang 184 passenger drone capable of carrying one person over short distances (Phillips, 2016). The possibility of being carried directly to your destination without the inconvenience of airports, local/national/international security protocols, or surface traffic could be appealing enough to mitigate fears of autonomy.

These developments and the associated media dialog suggested a continuation and update of the previous research by Vance (2014), and Vance \& Malik (2015) would be timely for the following purposes:

- Compare the current propensity for autonomous, passenger-airline travel to results of previous research

- Reassess the propensity for autonomous, passenger-airline travel

- Identify and correct previous misconceptions uncovered by Vance \& Malik (2015) History of Previous Autonomous Passenger Literature

Six, previous, directly applicable, research investigations to the posed, research question (spanning from 2003 -2018) will be briefly profiled in this sub-section.

\section{MacSween-George (IEEE) - 2003}

The first, known, dedicated research on the propensity for autonomous, air travel are two studies by MacSween-George, both published in 2003. The first is from IEEE Aerospace Conference Proceedings; the second is from AIAA proceedings. The AIAA article was the statistical launching point for Vance's 2013 research. MacSween-George is likely the first published researcher to simply ask the question, "Will people fly on autonomous airliners?"

MacSween-George hypothesizes "The majority of the flying public, when educated on the safety, reliability, and availability of pilotless aircraft for commercial airline cargo and passenger transportation, will significantly accept them as compared to those who have not 
been educated." MacSween-George surveyed a total of $n=120$ respondents. Half of those respondents were provided with a survey containing four, survey questions:

1. Would you support the Federal Aviation Administration (FAA) in allowing automated (unmanned) aircraft to transport cargo (Fed-Ex, UPS, etc.)?

2. Would you fly in an automated (unmanned) aircraft for business?

3. Would you fly in an automated (unmanned) aircraft for pleasure trips?

4. Would you fly in an automated (unmanned) aircraft if it were $50 \%$ cheaper than regular fares?

The other half of respondents were provided with the same four questions preceded by a short paragraph educating respondents on human-error rates and the autonomy benefits of reducing the possibility of hijacking.

Respondents to both surveys were given three response choices to each question; "Yes," "No," or "Not Sure." Responses were totaled, and a one-dimensional, chi-square calculation was performed to determine if the differences between the "uneducated" responses and the "educated" responses were statistically significant. The educational paragraph was found to statistically influence the responses on questions 2, 3, and 4 but not on question 1. The "with", and "without education", "Yes, I would fly on an autonomous airline" percentages are shown in table 1.

Table 1. MacSween-George's (IEEE) research shows that in 2003, even with a brief education on the benefits of autonomous flight and with a $50 \%$ discounted fare, only $17 \%$ of respondents indicated they would fly on an autonomous airliner.

\begin{tabular}{|lccc|}
\hline \multicolumn{4}{|c|}{ MacSween-George IEEE Results (2003) } \\
$\begin{array}{l}\text { Without Education } \\
\text { "Yuestion \# }\end{array}$ & $\begin{array}{c}\text { With Education } \\
\text { "Yes" \% }\end{array}$ & Average "Yes" \% \\
\hline 1) FAA autonomous cargo? & $37 \%$ & $52 \%$ & $45 \%$ \\
2) Fly for business? & $12 \%$ & $10 \%$ & $11 \%$ \\
3) Fly for pleasure? & $15 \%$ & $13 \%$ & $14 \%$ \\
4) Fly with 50\% discount? & $12 \%$ & $17 \%$ & $15 \%$ \\
\hline
\end{tabular}

\section{MacSween-George (AIAA) - 2003}

In the second paper, MacSween-George hypothesizes, "[the] Public's support of the FAA on Unmanned Aerial Vehicle (UAV) implementation of commercial, cargo, and passenger transportation will significantly increase when educated on a combination of statistical and emotional inferences of UAVs, compared to being provided minimal information on UAVs." In this version of her research, MacSween-George convenience surveyed a total of $n=200$ respondents. Each respondent was given a survey featuring these four questions preceded with a different preamble, cataloged as form A, B, C, or D: 
1. Would you support the FAA in allowing UAVs to transport cargo (Fed-Ex, UPS, etc.)?

2. Would you support the FAA in allowing UAVs for humanitarian and commercial uses such as firefighting and crop dusting?

3. Would you support the FAA in allowing UAVs for passenger transportation?

4. Would you personally fly in an automated (unmanned) aircraft?

Form A's preamble contained minimal data about UAVs. Form B contained statistical data that supported the use of UAVs. Form $C$ contained emotional, non-statistical safety references. Form $D$ contained a combination of forms $B$ and $C$. Each survey form was solicited in an identical quantity of 50 .

Respondents to all forms were given three response choices to each question; "Yes," "No," or "Not sure." Given the choice to travel is a dichotomous question, the current research, as well as Vance \& Malik (2015), considered the "No" and "Not sure" responses identical and also used a chi-square statistic to determine significance. Table 2 illustrates the results from this survey.

Table 2. The most significant takeaways from MacSween-George (AIAA) are the high-percentage acceptance of autonomous cargo operations (50.5\%) and the low-percentage acceptance of people that were willing to be a passenger on an autonomous airliner (10.5\%).

\begin{tabular}{|c|c|c|c|c|c|}
\hline \multicolumn{6}{|c|}{ MacSween-George AIAA Results (2003) } \\
\hline Question \# & Form A "Yes" & Form B "Yes" & Form C "Yes" & Form D "Yes" & Average "Yes" \\
\hline 1 & $38 \%$ & $48 \%$ & $48 \%$ & $68 \%$ & $51 \%$ \\
\hline 2 & $54 \%$ & $54 \%$ & $50 \%$ & $34 \%$ & $48 \%$ \\
\hline 3 & $12 \%$ & $10 \%$ & $17 \%$ & $16 \%$ & $14 \%$ \\
\hline 4 & $6 \%$ & $8 \%$ & $16 \%$ & $12 \%$ & $11 \%$ \\
\hline
\end{tabular}

Tam - 2011

Tam (2011) surveyed members of the International Society of Aircraft Traders and Purdue University faculty to determine the perception of air travelers toward the use of unmanned aircraft systems (UAS) for passenger travel. The generally older ( $53 \%$ between the ages of 50-64), airline-travel-experienced respondents were not in support of a "fully automated UAV airliner" or a "UAV airliner controlled from the ground." Only 13\%* indicated support for this mode of airline travel. Most respondents $\left(78 \%^{*}\right)$ supported a fully autonomous airliner if a backup pilot was onboard. Participants were generally more accepting of UAV use for cargo transport. The study was unable to correlate a relationship between levels of acceptance and demographic data or knowledge of UAS. ${ }^{*}$ Note: since Tam did not disclose actual data, the quoted percentages were derived from the presented bar graphs. 


\section{Vance - 2013}

Vance's previous research (2014) investigates factors that influence opinion in the decision to fly on fully autonomous, passenger airliners primarily from the perspective of aviation and technology professionals. Data was collected over the month of October 2013. While the Qualtrics ${ }^{\mathrm{TM}}$ on-line survey sites and the unsolicited e-mail proliferation directing recipients to the Qualtrics ${ }^{\mathrm{TM}}$ survey used to collect the data were theoretically random and public, the samples, as evidenced in the survey solicitation comments, are heavily aviation and science/math vocationally based. When mathematical reduction was used to estimate a true public survey, the resulting percentage of the population willing to fly on an autonomous airliner was $32.8 \%$. A total of $n=1,794$ surveys were started, with $n=1,506$ ( $84 \%$ ) surveys remaining useable.

Prior to completing any portion of the research survey, respondents were queried for their willingness to consider autonomous-airliner travel. This input was then coupled with the prior MacSween-George 2003 (AIAA) data in a Bayesian-statistical-inference update. A twolevel-fractional-factorial, vignette-based survey was then used to sample passengers' views on fully autonomous airliners, principally because vignette (story)-based research has proven to be more engaging in eliciting accurate survey results (Ludwick and Zeller, 2001; Wallander, 2009). Eight, trust, safety, cost factors (the independent variables) were incorporated into an eightparagraph, vignette set in the future. Each paragraph contained one variable, while the order of the paragraphs was constant. The variable wording depended on which level the variable was set, either hypothesized to be least influential or most influential in the decision to fly on an autonomous airliner. Factors (variables) included a) automation sophistication (of both the airliner and air traffic system), b) federal, regulatory structure (of the air transport system), c) air transport system response to interruptions, d) number of years of uneventful, unmanned, cargo operations, e) unmanned, cargo-flight, safety record, f) contracts and guarantees by the providing company (the airline), g) displayed service provider characteristics (again, the airline), and $\mathrm{h}$ ) ticket price reductions (compared with today).

The eight factors (variables) at two-levels each produced a full factorial of $2^{8}=256$ unique vignettes. A NIST (National Institute of Standards) 1/16 fractional factorial was employed to reduce the total number of unique vignettes to 16 . The Qualtrics ${ }^{\mathrm{TM}}$ survey tool randomized which of the 16 vignettes was presented to each respondent. The 16 versions of the vignette, each with unique trust, safety, and cost levels, presented varying (unknown) degrees of influence to the survey respondents. The research was able to statistically reduce the amount of influence each level of each factor had on the decision to fly aboard an autonomous airliner.

Dependent variables existed in five, post-vignette questions and concluded with, "Would you" or would you not be willing to fly on a fully autonomous airliner?" Bayesianstatistical-inference was used to compare the post-vignette responses to those at the beginning

of the research survey. This research was then able to display two Bayesian updates of the 
2003 MacSween-George data, the first with the opening-research question and the second with essentially the identical, closing-research question.

For every demographic collected, the research showed a 99\% statistically significant difference between the "prior" and "posterior" sampled population proportions willing to fly. The most significant, positive influence involved the integrity characteristics of the airline; the most negative influence related to life-insurance-liability guarantees. The MacSween-George 2003 (AIAA) research suggested this mode of travel would be acceptable to only $10.5 \%$ of respondents. When the 2003 research was used as the first, Bayesian-prior probability for the opening 2013 research "Would you fly?" question, the resulting Bayesian-posterior probability grew to $27.1 \%$ willing to fly. After completing the 2013 vignette-based survey, the second posterior-Bayesian update for the demographics sampled were modeled as a beta distribution, with a mean $(\mu)=34.8 \%$ and a $95 \%$ probability the sampled proportion of the population willing to fly between $33.2 \%$ and $36.4 \%$. After adjusting for age and profession demographics to match the U.S. population, the mean reduced slightly to $(\mu)=32.8 \%$ with a $95 \%$ probability the sampled proportion of the population willing to fly was between $31.35 \%$ and $34.15 \%$.

\section{UBS - 2017}

In 2017, UBS (formerly the Union Bank of Switzerland) released a survey on passengers' propensity to travel on autonomous airliners (Castle, et.al, 2017). Their survey was distributed in the U.S., U.K., France, Germany, and Australia in April and May of 2017 and was their third round of research on this topic. Global respondents totaled $n=7,940$ with U.S. respondents totaling $n=1,507$. As a global investment firm, their discussion revolved around investment opportunity and autonomous airliners effect on industry investments including avionics manufacturers, Original Equipment Manufacturers (OEMs), and the airlines themselves. The authors quickly noted autonomous airliners are technologically feasible and the two significant factors restraining autonomy are regulation and perception; with perception being the greatest. Of nearly 8,000 global respondents, $17 \%$ indicated they were either "very likely" or "somewhat likely" to take a pilotless flight with $54 \%$ responding either "very unlikely" or "somewhat unlikely." While not clarified in the report, it was assumed the remaining percentage fell into an "unsure" category.

The 1,507 U.S. respondents were more likely than the global respondents to take an autonomous airliner flight, $27 \%$ likely and 50\% unlikely. The UBS data confirms the Vance-2014 hypothesis of younger travelers being more likely to take autonomous, airliner flights than older travelers. The UBS study found more highly educated, higher paid people are more likely to travel autonomously. Respondents were also polled, "How much cheaper should the pilotless flight ticket be so the respondent would buy it?" The results are shown in Figure 1. Note that $50 \%$ responded, "I would not buy, even if cheaper." 


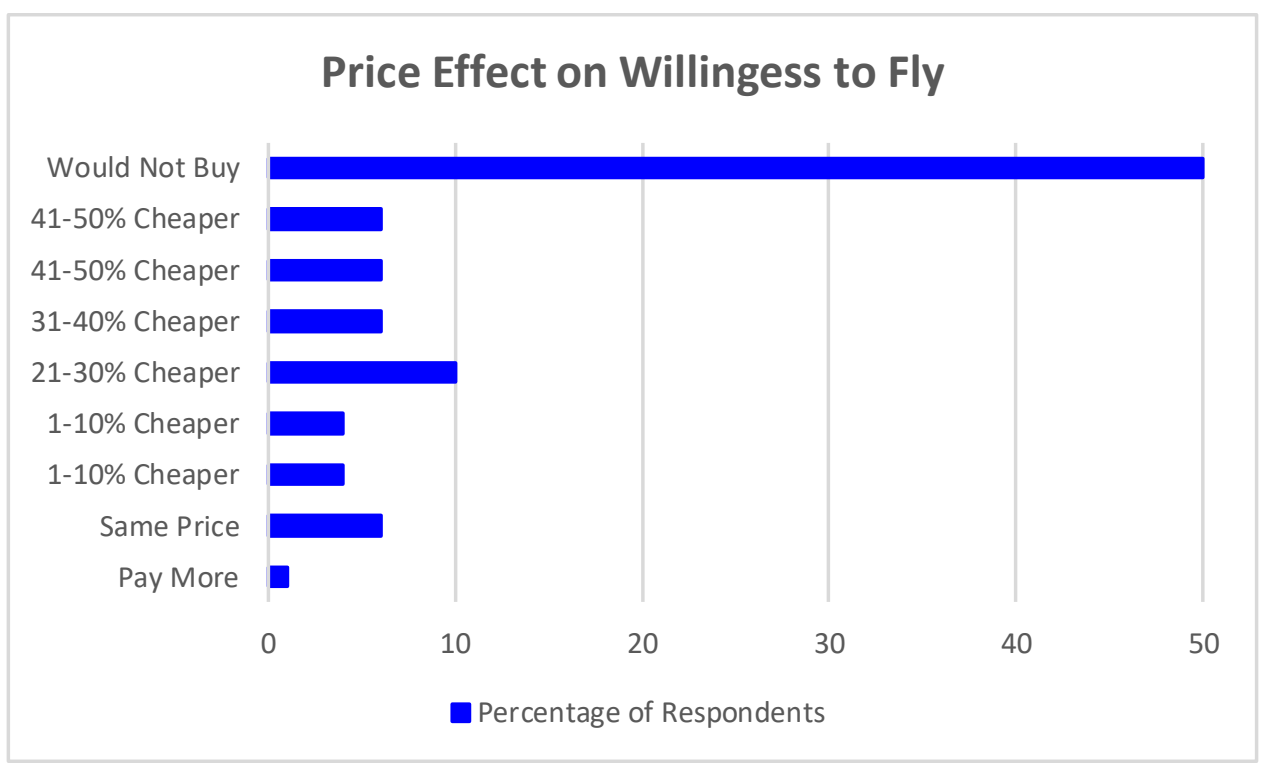

Figure 1. The UBS study's price elasticity is shown dominated by the "Would Not Buy" decision.

\begin{abstract}
ALPA - 2018
In a summer 2018 survey conducted by the Air Line Pilots Association, International (ALPA) of $n=1,109$ Americans (ALPA, 2018; Galford, 2018; Isops, 2018), the responses were:

- $81 \%$ expressed opposition to removing pilots from cockpits based on safety rationale.

- $80 \%$ demanded two pilots working together as the best option for operating aircraft.

- $73 \%$ opposed proposals to reduce training and experience requirements.

- $8 \%$ favored investing in technology to eliminate one or both pilots from the cockpit.

\section{Trends}

Figure 2 plots an exponential, best-fit line between the two MacSween-George (2003) surveys, Tam (2011), Vance \& Malik (2015), UBS (2017), and ALPA (2018) and clearly shows an increase in propensity over the past 15 years. However, the overall acceptance levels are still significantly below the typically $50 \%$ level considered minimally necessary for early market adoption (Britt \& Nelson, 1976). The cause for bias or mistrust of automation may be cultural in nature (Rice, et.al, 2014), could stem from the military origins of UAS technology, or (likely) is simply rooted in lack of trust (Levin, 2018; Little, 2019).
\end{abstract}




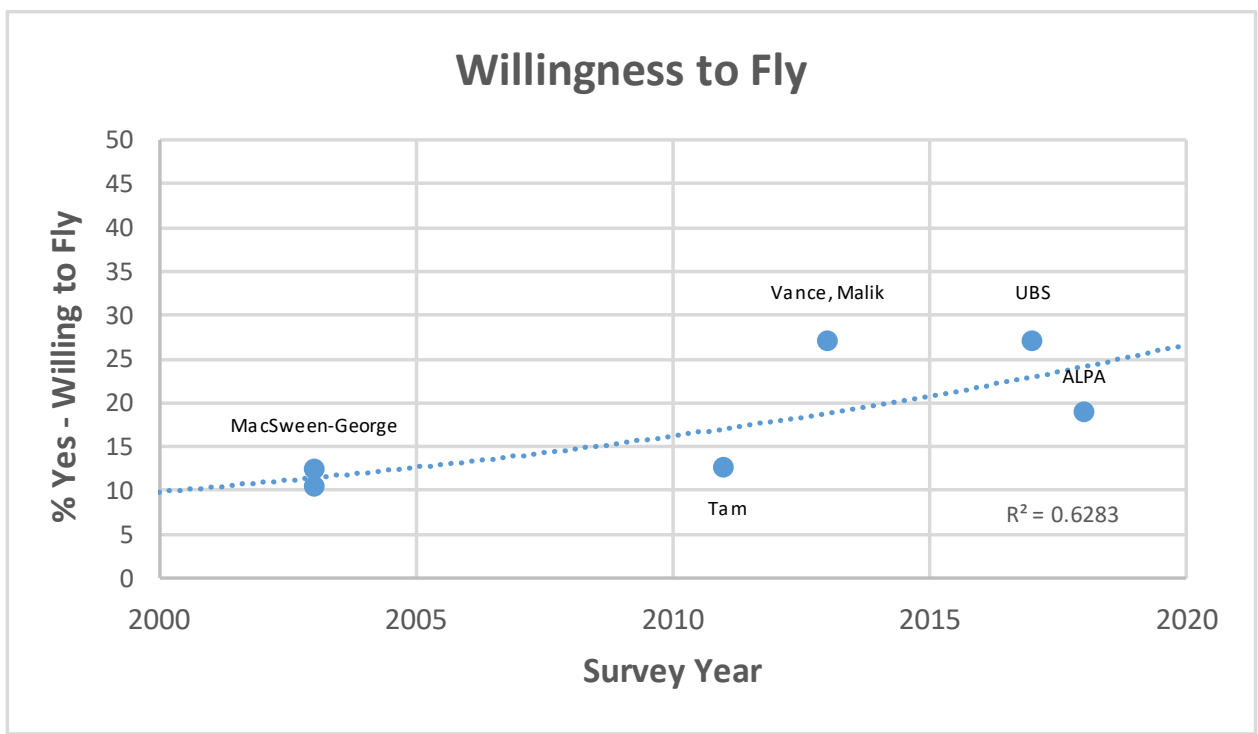

Figure 2. The propensity to consider autonomous, airliner travel is simplistically shown trending over six studies which directly probed on the "Would you fly on an autonomous airliner?" question.

A possible negative, UAS influence on public perception was the U.S. military use of UAS in Iraq and Afghanistan, at first for surveillance and later for missile strikes, which resulted in a high, civilian casualty rate (Wheatley, 2006). These events sparked international controversy surrounding UAS, in which the technology received a largely negative spotlight, and potentially planted seeds of mistrust in the minds of the public in regards to the safety of UAS.

Another possible concern with the technology necessary to facilitate autonomous airliners is the possibility of "cy-jacking," hacking into autonomous airliners to conduct nefarious actions. Dr. Nicola Bezzo, whose research revolves around the security of cyberphysical systems, is quoted in Kelly (2017), "I believe we are never going to be able to completely solve this [security] problem." The corresponding certification issues are also significant as discussed by Mutuel (2013).

There is no question that the public remains more "against" than they are "for" the use of autonomous airliners, but recent events and articles suggest a steady, positive shift in public opinion favoring autonomous, airliner travel. The idea of autonomous vehicles not only being safer but more convenient and faster than conventional travel may be beginning to sink into the general population as evidenced by the billions of dollars invested by 33 corporations such as Google and General Motors in autonomous vehicles (CB Insights, 2016). Uber's investment in "flying taxis" would suggest these companies are willing to invest in autonomous transport, and they are willing to bet if they can develop the technology, people will use the service (CB Insights, 2016; Uber Elevate, 2016; Clayton, Hughes, Rice \& Trafimow, 2009). The surge in periodical articles in recent years also reinforces the speculation that fully autonomous airlines are gaining acceptance. Owens (2017), Rice (2019), Rice \& Winter (2019), Ridley (2014), Ross 
(2011), Stewart (2014), Stickles (2016), Stouffer (2015) are but a few of many examples. Keyword search "pilotless airliners" to sample numerous others.

The following hypothesis is derived from the literature review:

$\mathrm{H}_{\mathrm{a}} \mathrm{I}$ - There is a statistically significant difference in the general population's valuation of travel aboard an autonomous airliner in 2018 than previously reported for the predominantly aviation, science and technology sample taken in Oct 2013.

\section{Methodology}

The methodology employed by Vance (2014) has been repeated here, i.e., Bayesianstatistical-inference married with a fractional-factorial, vignette-based survey. These methods appropriately address the research question. For specific questions regarding the use of either Bayesian-statistical-inference or fractional-factorial, vignette-based survey methods, the reader is referred to methodology sections of either Vance (2014), or Vance \& Malik (2015).

The specific acceptance of autonomous, airliner travel data points used in the Bayesian updates presented in this research include: MacSween-George 2003 results, opening question of Vance's 2014 research, and the opening question of this 2018 research. Neither closing question of either Vance's 2014 research nor this 2018 research were included in this longitudinal-Bayesian update because each represents a qualified, acceptance rate based on the influence of the vignette-based survey; however those end state percentages are useful to understand the potential implications of addressing passenger's concerns regarding the specific Independent Variables (IVs) communicated through the vignette-based survey.

There are two aspects of this updated research that are methodologically different from Vance (2014) and Vance \& Malik (2015). First, this updated research adjusts Vance's previously researched IVs that produced abnormal results either due to potential wording issues or the abstractness of the propositions. Second, a 3-level, fractional factorial was selected, instead of repeating the use of a 2-level, fractional factorial, to potentially raise the fidelity of insight that can be derived from the results. Figure 3 illustrates the significant, potential fidelity that a 3-level variable can offer over the limited, linear relationship derivable from a 2-level variable. 

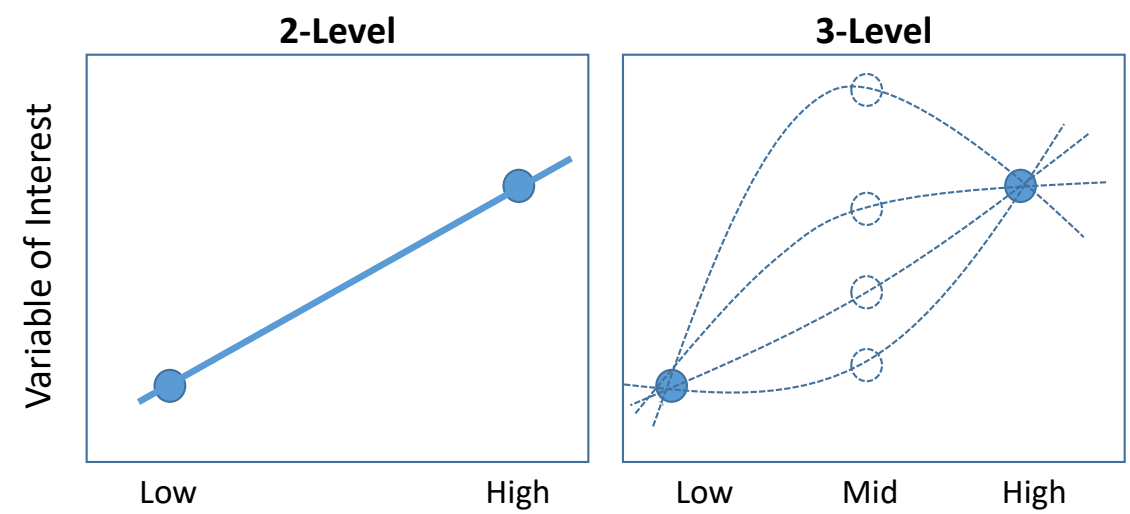

Figure 3. A 3-level variable offers more insight into the behavior of the variable at points between and beyond the sampled range (assuming a continuous, non-linear relationship); whereas, a 2-level variable only allows a linear interpolation between the sampled points and no insight to points beyond that sampled.

The significant challenge using a 3-level design of experiments is the limited number of variables that can efficiently be considered and the lack of insight into their interactions. Simply transitioning an existing 2-level variable experiment to a 3-level variable experiment is not straight forward, requires care, and can complicate the mathematical reduction beyond the point of adding value into the desired analysis. The National Institute of Standards web resource (NIST, 2018) cautions that one disadvantage of a 3-level design is "...they provide limited information about interactions". Based on the initial 2014 research completed by Vance, this limitation was deemed acceptable as the then-documented-interaction analysis showed no significant, additional, research insights.

Table 3 shows the eight variables and their negative (-) and positive (+) 2-level definitions published in the Vance (2014) and Vance \& Malik (2015) vignette-based research. The negative level (-) of each variable was postulated to be the least influential; correspondingly, the positive level (+) was postulated to be the most influential on the decision to fly aboard an autonomous airliner. The first seven variables and their "-/+" levels were derived from the literature reviewed at the time. The eighth variable (ticket price cost) was included because cost always influences a commodity purchase. The "+" ticket price cost level was purposefully set at an aggressive reduction, but done so without marketing insight or research.

Table 3. Table 2, in Vance's 2014 research, reprinted verbatim for quick reference. 
Table I. 2013 survey independent variables and their $(-) /(+)$ levels*.
(-) Postulated to be least influential
(+) Postulated to be most influential

\section{A. (Trust)—automation sophistication}

Standard technology that experiences occasional

Proven technology reinforced with sophisticated

lapses that are sometimes newsworthy and artificial intelligence that experiences extremely disruptive to daily operations rare lapses. Even if lapses do occur, the transportation system computer networks heal so quickly that lapses are neither noticeable nor newsworthy

US government-sanctioned, hands-off, B. (Trust) - federal regulatory structure

self-regulating approach (known as "laissez faire") where market supply and US government structure similar to today's structure demand dictate the quality and safety of service that tracks airline performance, competition, and safety standards

\section{C. (Safety/trust)—system response to interruptions}

Mechanical vehicle malfunctions, even if the vehicle airliner must operate in a degraded state and receive specialized handling. Emergencies, severe weather, and rogue/terrorist actions still require the intervention of real-time human decision making for the affected airliner(s). When handled promptly, the impact of the affected airliners(s) to the overall, safe operation of the transportation system is Mechanical malfunctions and emergencies, the effects of severe weather, single or multiple synchronized criminal/terrorist threats, no matter whether the threats are from on board the airliner (sabotage) or remotely transmitted to the airliner(s). The transportation system and the affected airliners operating in the system are able to absorb these significant physical and cyber disruptions with acceptable, safe, survivable workarounds and minimal-to-zero disruptions in service manageable, but it is noticeable
2 to 5 years 25 years (approximately one human generation)
E. (Safety)—unmanned cargo flight safety record
One fatal accident per year One fatal accident every 10 years
F. (Trust) - contracts and guarantees by the providing company 1 year's US Department of Transportation 10 years' US Department of Transportation value of value of life (\$6m, in 2013 dollars) life (\$60m, in 2013 dollars)

\section{G. (Trust)—displayed service provider characteristics}
Transparency, by openly presenting its (i) moral integrity by openly presenting its safety safety record and resolving unsafe practices record and resolving unsafe practices; (ii) investments in up-to-date technology, which is evident in all aspects of their operations; and (iii) that it shoulders the fiduciary responsibility for safe passage of its passengers and has demonstrated that responsibility during past crises with settlements and in the way it cares for and handles passengers affected by a crisis

D. (Trust)—number of years of uneventful unmanned cargo operations (A-H) levels.

Identical to the current, updated research, the Vance (2014) research was purposefully bracketed with essentially the same question at the beginning and the end of the respondent survey to facilitate an unbiased, Bayesian update of the most recently selected research. In the case of Vance (2014), the update was of the 2003 MacSween-George results. Once the opening question was asked and answered, the respondent was introduced to new evidence, e.g., the Vance (2014) vignette-based survey - which was titled "A Glimpse into the Future". To allow a final, Bayesian-update opportunity, after the respondent had completed the survey, the respondent was presented with essentially the identical closing question as the opening question. The exact wording, bookkeeping codification, and associated response scale of the bracketing questions from Vance's (2014) work are as follows (italics indicate a survey 
instrument component viewable by a respondent):

Opening question (QO) (was asked immediately after a respondent had read the consent information and (importantly) prior to any other survey information/queries) - "Given your knowledge and understanding of today's automation technology, what is the overall likelihood, in the foreseeable future, you would travel as a passenger on an unmanned, autonomous, passenger airliner?"

Please indicate your response by checking a single percentage box below

(For example: Would not travel $=0-10 \%$, Would travel $=90-100 \%$ ):

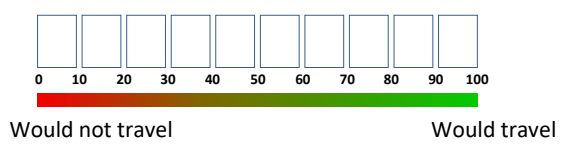

Survey vignette - A Glimpse into the Future

Closing questions (Q1-Q4) [These were not included in the current, updated research]

Closing question (Q5) - Given "A Glimpse into the Future" becomes reality, what is the overall probability you would be willing to fly on a new, unmanned, autonomous, passenger airliner?

Please indicate your response by checking a single percentage box below

(For example: Low Probability $=0-10 \%$, High Probability $=90-100 \%$ ):

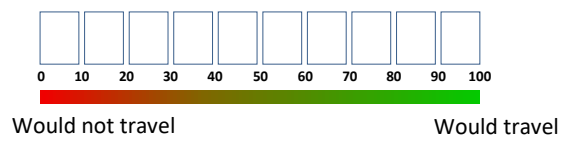

The identical opening and closing approach was used in the current, updated research with the exception of only one closing question, not five as done previously; closing questions Q1) - Q4) from the 2014 research were eliminated as they were not assessed as adding value. Table 4 shows a summary of the factorial results from Vance (2014) Figure 37. The columns in the table represent from left-to-right: column 1 ) the number of respondents $(n)$ per vignette, column 2) mean of the response to the opening question (Q0), column 3 ) the vignette number $1-16$, columns $4-11)$ the $(+1)$ or $(-1)$ level to which each main effect $(A-H)$ was set in each of the 16 vignettes, columns 12-17) the mean of each of the Dependent Variable (DV) questions (Q1-Q5B) mapped with each of the vignettes. To further clarify, column 16) Q5F-Fly connotes the Frequentist (means-based) calculation for DV5, and column 17) Q5B-Fly connotes the Bayesian-statistical-inference "No = Will not Fly/Yes = Will Fly" calculation for DV5. Notice the very minor differences between these two, different, mathematical approaches. If the raw data had been more "normal" in distribution, verses its bi-modal shape, the differences would be even smaller; even as is, the differences in calculation technique are negligible.

Much can be learned by inspection of the results shown in Table 4. 
Table 4. Vance (2014) 8-variable, 2-level results are shown mapped against each of the 16 vignettes. Both the prior question (Q0) and the follow-on questions Q1-Q5 results are shown, by vignette. The fifth follow-on question (DV) is shown with both a Frequentist (means-based) approach (Q5F) and a Bayesian ("No = Will not Fly/Yes = Fly") approach (Q5B).

\begin{tabular}{|c|c|c|c|c|c|c|c|c|c|c|c|c|c|c|c|c|c|}
\hline \multicolumn{4}{|c|}{ Prior } & \multicolumn{7}{|c|}{8 factors, 2-levels each } & \multicolumn{7}{|c|}{ Posterior } \\
\hline & $n$ & QO & Vignette & A & B & C & D & $\mathbf{E}$ & $\mathbf{F}$ & G & H & Q1 & Q2 & Q3 & Q4 & $\mathrm{Q} 5 \mathrm{~F}$ & Q5B \\
\hline & 93 & 29 & 1 & -1 & -1 & & -1 & -1 & -1 & & -1 & 49 & 32 & 40 & 33 & 39 & 36 \\
\hline & 93 & 32 & 2 & 1 & -1 & & -1 & -1 & 1 & 9 & 1 & 54 & 37 & 38 & 31 & 43 & 43 \\
\hline & 94 & 29 & 3 & -1 & 1 & & -1 & 1 & -1 & & 1 & 51 & 35 & 46 & 32 & 42 & 39 \\
\hline & 103 & 32 & 4 & 1 & 1 & & -1 & 1 & 1 & & -1 & 51 & 33 & 40 & 26 & 34 & 34 \\
\hline & 93 & 35 & 5 & -1 & -1 & & -1 & 1 & 1 & 1 & -1 & 54 & 37 & 44 & 33 & 46 & 48 \\
\hline & 89 & 29 & 6 & 1 & -1 & 1 & -1 & 1 & -1 & -1 & 1 & 58 & 40 & 47 & 33 & 45 & 47 \\
\hline & 98 & 29 & 7 & & 1 & 1 & -1 & -1 & & -1 & 1 & 52 & 37 & 40 & 31 & 40 & 42 \\
\hline & 103 & 37 & 8 & & 1 & & -1 & -1 & & 1 & -1 & 59 & 41 & 48 & 35 & 48 & 53 \\
\hline & 97 & 29 & 9 & & -1 & & 1 & 1 & & & 1 & 52 & 36 & 40 & 27 & 38 & 38 \\
\hline & 87 & 35 & 10 & & -1 & -1 & 1 & 1 & -1 & 1 & -1 & 61 & 48 & 39 & 48 & 50 & 51 \\
\hline & 92 & 28 & 11 & & 1 & -1 & 1 & -1 & & 1 & -1 & 49 & 36 & 38 & 36 & 40 & 39 \\
\hline & 89 & 31 & 12 & & 1 & -1 & 1 & -1 & & -1 & 1 & 62 & 42 & 44 & 40 & 48 & 53 \\
\hline & 93 & 35 & 13 & -1 & -1 & 1 & 1 & -1 & -1 & 1 & 1 & 60 & 43 & 45 & 39 & 47 & 49 \\
\hline & 90 & 30 & 14 & 1 & -1 & 1 & 1 & -1 & 1 & -1 & -1 & 58 & 41 & 46 & 34 & 42 & 41 \\
\hline & 103 & 33 & 15 & -1 & 1 & 1 & 1 & 1 & -1 & -1 & -1 & 53 & 35 & 50 & 29 & 41 & 41 \\
\hline & $\underline{89}$ & $\underline{31}$ & 16 & 1 & 1 & 1 & 1 & 1 & 1 & 1 & 1 & $\underline{55}$ & $\underline{39}$ & $\underline{39}$ & $\underline{42}$ & $\underline{46}$ & $\underline{49}$ \\
\hline$\Sigma$ & 1506 & 504 & & & & & & & & & & 878 & 614 & 684 & 550 & 689 & 702 \\
\hline $\boldsymbol{\mu}$ & 94 & 31 & & & & & & & & & & 55 & 38 & 43 & 34 & 43 & 44 \\
\hline$\sigma$ & 5 & 3 & & & & & & & & & & 4.2 & 4.0 & 3.8 & 5.6 & 4.4 & 6.1 \\
\hline
\end{tabular}

Observe that in Vignette 1, when all eight factors (IVs) are set at their (-) levels, the results are predictably a low response in the decision to fly (Q5F or Q5B) but not the lowest response; that result was achieved with Vignette 4, independent of calculation method, either Frequentist or Bayesian. Correspondingly, Vignette 16, when all the factors are set at their (+) levels does not result in the highest response in the decision to fly; that result is driven by Vignette 10 when Frequentist calculated, and by Vignettes 8 and 12 when Bayesian calculated. This suggests not all of the main effect $(+)$ levels are as influential as they had been anticipated to be, there may be negative main effect interactions occurring in Vignettes 1 and 16 (and other vignettes too), or reluctantly, there is the possibility of both issues occurring.

It can also be observed, by inspection, that Vignettes 8,10 and 12 are responsible for the highest, three, response means in the decision to fly (Q5F or Q5B). Conversely, Vignettes 1, 4, and 9 are responsible for the lowest, three, response means in the decision to fly (DV5). Light green and red are used to respectively highlight these six vignettes. Note also these highest and lowest scoring vignettes are independent of statistical analysis method, i.e., both the Frequentist (Q5F) and Bayesian-statistical-inference (Q5B) columns are consistent in this pattern.

Furthermore, it can be observed (via the small green circles in Table 4) the main effects A) Automation Sophistication (at the + level), and F) Contracts \& Guarantees by the Providing Company (at the - level) are consistently associated with the highest, three, response means in the decision to fly (DV5). Conversely, it can also be observed (via the small red circles in Table 4) the main effects C) System Response to Interruptions (at the - level) and G) Displayed Service Provider Characteristics (at the - level) are consistently associated with the lowest, 
three, response means in the decision to fly (DV5). Thus, inspection of the main effects on the principal, dependent variable of interest (DV5 - to "Fly" or "Not Fly" on an unmanned, autonomous airliner) shows four of the eight main effects as consistently influential across at least six versions of the vignettes. Three of these, variables $A, C$ and $G$, behaved as expected; $F$ behaved opposite of what was expected.

As shown in Vance (2014) and in Vance \& Malik (2015), IVs B) Federal Regulatory Structure, E) Unmanned Cargo Safety Flight Record, and F) Contracts and Guarantees by Providing Company returned illogical responses. Specifically the average of each variable when set at the positive level $(+)$ returned a response inferior to the average of the negative level (-); this is the opposite of what was expected when the levels of the variables were set. Variable $\mathrm{H}$ ) Ticket Price Reduction also did not have as strong of a positive response as expected. Figure 4 reprints Vance (2014) Figure 58 for edification, showing the overall impact of each IV on the "Would You Fly?" question (DV5). These results are the apportioned percent of the overall, DV5 Bayesian-calculated $44 \%$ who indicated a willingness to fly as influenced by each respective IV, A-H.

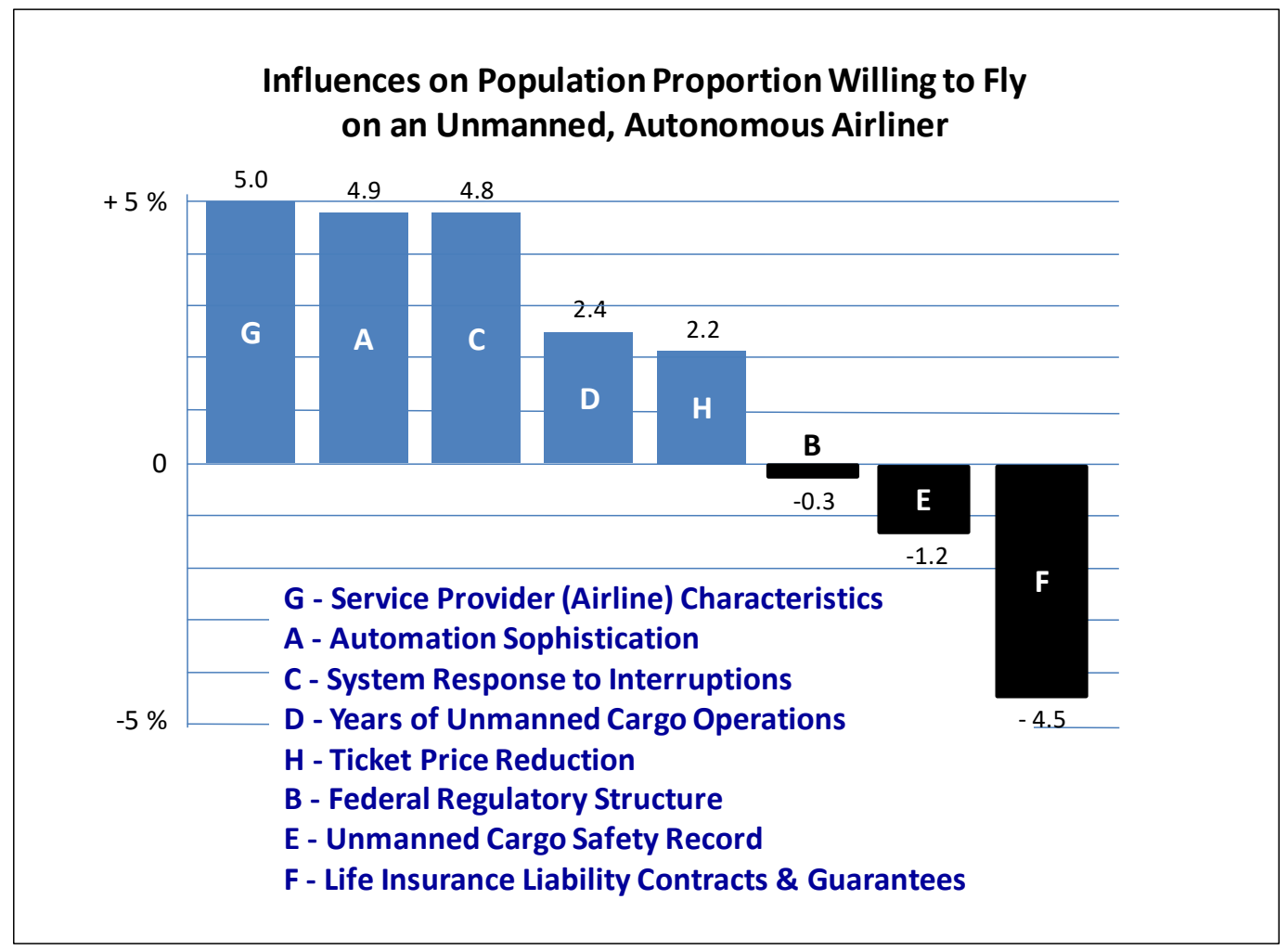

Figure 4. The unexpected negative influence of IVs B, E and $F$ on the willingness to fly question (DV5) is evident. The differing, respective levels show $B$ as marginally negatively influential (in fact, this was not statistically significant, at even $\alpha=.05$ ) and $F$ as significantly negatively influential (and statistically significant at $\alpha=.01$ ). The values shown were calculated with the Bayesian "No = Will not Fly/Yes=Fly" mathematical approach. The Frequentist numbers show the identical trends, but the values in all cases are smaller - see Vance \& Malik (2015) for further explanatory details. 
Based on these results and observations from Vance \& Malik (2015), there are at least three IVs ( $B, E$ and $F)$, and possibly a fourth IV $(H)$ for either modification or potential elimination from the current, research update. These four IVs were either modified or eliminated in the current, updated research as indicated by the following rationale:

\section{B) Federal Regulatory Structure - Eliminate}

For this study, we assumed the commercial air carrier industry will continue to be regulated at a level similar to today and this influence, either positively or negatively, was not a discriminator in the willingness to fly on an autonomous airliner.

\section{F) Life Insurance Liabilty Contracts \& Guarantees - Eliminate}

While flight accident insurance is still purchasable, accident-insurance kiosks are long gone from airports and this issue does not appear relevant in the public-travel-mindset. "Flight insurance is definitely not worth spending money on," says Jack Hungelmann, the author of Insurance for Dummies. "If you buy flight insurance, what you're really saying is, 'I'm scared to death that I don't have enough life insurance if I die.' What you should do instead is buy a cheap term life policy." (MacDonald, 2008). Additionally, the value-of-life figures posed in the Vance (2014) research as insurable were so large (\$60M when set at the + level, and \$6M when set at the - level) as to likely not have been credible/believable payouts per passenger.

\section{E) Unmanned Cargo Safety Record - Eliminate}

We believe this IV was worded in a way in the Vance (2014) research to make the positive level still appear negative. The essence of this IV is already covered in the IV, E) Years of Unmanned Cargo Operations, thus making this IV duplicative and available for elimination.

\section{H) Ticket Price Reduction - Revise}

There are two trains of thought regarding ticket price reduction a) lower ticket prices encourage usage because flights are more affordable, and b) lower prices imply lesser quality thus turning away consumers. The three, revised levels used in this updated research each allow increasingly modest, equal-interval, price reductions (15\%, $25 \%$ and $35 \%)$. In this manner, the perceived, service quality may not be as greatly diminished and the price reductions may still be increasingly enticing.

A simple, 3-level, fractional-factorial, orthogonal-array design compatible with the now five variables was needed; however, there were no orthogonal arrays optimized for five variables.

There is a popular, vetted, 4-varialbe, orthogonal-array available - the Taguchi L9 array (Ross, 1998) which examines at resolution level III, four variables at 3-levels each, in a total of nine experimental runs. Table 5 illustrates this array and the level to which each variable is set 
for the respective experimental run.

Table 5. A standard Taguchi Ls, orthogonal array accommodates the examination of four variables at 3-leves each in nine, experimental runs employing either a negative $(-1)$, intermediate (0), or positive (1) level. This table shows the script for how each variable level must be set in each of the nine experiments. In this research, each of the nine vignettes were randomly presented to respondents.

\begin{tabular}{ccccc}
\hline Run & A & B & C & D \\
\hline 1 & -1 & -1 & -1 & -1 \\
2 & -1 & 0 & 0 & 0 \\
3 & -1 & 1 & 1 & 1 \\
4 & 0 & -1 & 0 & 1 \\
5 & 0 & 0 & 1 & -1 \\
6 & 0 & 1 & -1 & 0 \\
7 & 1 & -1 & 1 & 0 \\
8 & 1 & 0 & -1 & 1 \\
9 & 1 & 1 & 0 & -1 \\
\hline
\end{tabular}

To be compatible with the introduced, Taguchi $L_{9}$, orthogonal array, a fourth variable needed to be eliminated from consideration - if H) Ticket Price Reduction was to be retained, that left three variables from which to choose for elimination, A) Automation Sophistication, C) System Response to Interruptions, and G) Service Provider Characteristics. All three are trustbased variables, but of these three, G) Service Provider Characteristics is distinguished from A) and $\mathrm{C}$ ) in being less technologically focused and significantly more dependent upon human choice and action than machine performance. Thus, the decision was made to blend characteristics of $A$ ) into $C$ ) since ultimately, the conviction of the researchers was passengers would care more about the ability of the technology to keep them safe than they would necessarily care about the assessed level of technology sophistication required to keep them safe.

This position left four variables for examination in this research. Table 6 shows the remaining variables, now cataloged as A), B), C) and D) and their associated definitions at the negative (-), intermediate (0), and positive (+) levels.

Table 6. The four remaining Independent Variables and their negative (-), intermediate (0), and positive (+) levels are shown. To set an IV level, a sentence fragment verbiage set from either the $(-)$, intermediate $(0)$, or $(+)$ column is inserted in the respective sentence in the vignette, shown to the left in the first column, replacing the bolded variable title displayed between the carrots ( $<$ Independent Variable $>$ ).

\begin{tabular}{|c|c|c|c|}
\hline \multicolumn{4}{|c|}{2018 Survey Independent Variables and Their (-), (intermediate), (+) Levels } \\
\hline & $(-)$ & (intermediate) & $(+)$ \\
\hline $\begin{array}{l}\text { The future air } \\
\text { transportation } \\
\text { systems are capable of } \\
\text { autonomously }\end{array}$ & $\begin{array}{l}\text { limited mechanical } \\
\text { malfunctions. More } \\
\text { serious mechanical } \\
\text { malfunctions, }\end{array}$ & $\begin{array}{l}\text { modest mechanical } \\
\text { malfunctions, even if } \\
\text { the airliner must } \\
\text { operate in a degraded }\end{array}$ & $\begin{array}{l}\text { extensive, previously } \\
\text { considered crippling, } \\
\text { mechanical } \\
\text { malfunctions / }\end{array}$ \\
\hline
\end{tabular}




\begin{tabular}{|c|c|c|c|}
\hline $\begin{array}{l}\text { handling <A: } \\
\text { Transportation } \\
\text { System Response to } \\
\text { Interruptions>. }\end{array}$ & $\begin{array}{l}\text { emergencies, severe } \\
\text { weather and rogue / } \\
\text { terrorist actions } \\
\text { require the direct and } \\
\text { immediate } \\
\text { intervention of real- } \\
\text { time, human decision } \\
\text { making for the } \\
\text { affected airliner(s). If } \\
\text { handled successfully, } \\
\text { the impact of the } \\
\text { affected airliner(s) to } \\
\text { the overall, safe } \\
\text { operation of the } \\
\text { transportation system } \\
\text { is obvious with } \\
\text { significant disruptions } \\
\text { in service. }\end{array}$ & $\begin{array}{l}\text { state and necessitate } \\
\text { specialized handling. } \\
\text { Emergencies, severe } \\
\text { weather and rogue / } \\
\text { terrorist actions } \\
\text { require remote } \\
\text { assistance/oversight } \\
\text { from real-time, human } \\
\text { decision making for } \\
\text { the affected } \\
\text { airliner(s). When } \\
\text { handled promptly, the } \\
\text { impact of the affected } \\
\text { airliner(s) to the } \\
\text { overall, safe operation } \\
\text { of the transportation } \\
\text { system is noticeable } \\
\text { with modest } \\
\text { disruptions in service. }\end{array}$ & $\begin{array}{l}\text { emergencies. } \\
\text { Additionally, the } \\
\text { system can handle the } \\
\text { effects of severe } \\
\text { weather, single or } \\
\text { multiple synchronized } \\
\text { criminal / terrorist } \\
\text { threats, no matter } \\
\text { whether the threats } \\
\text { are from on board the } \\
\text { airliner (sabotage) or } \\
\text { remotely transmitted } \\
\text { to the airliners(s). The } \\
\text { transportation system } \\
\text { and the affected } \\
\text { airliners operating in } \\
\text { the system are able to } \\
\text { absorb these } \\
\text { significant physical } \\
\text { and cyber disruptions } \\
\text { with acceptable, safe, } \\
\text { survivable } \\
\text { workarounds and } \\
\text { minimal-to-zero } \\
\text { disruptions in service. }\end{array}$ \\
\hline $\begin{array}{l}\text { Unmanned, } \\
\text { autonomous, cargo } \\
\text { flights have operated } \\
\text { safely for the past <B: } \\
\text { Number or Years of } \\
\text { Uneventful } \\
\text { Autonomous Cargo } \\
\text { Operations>. }\end{array}$ & 2-to-5 & 10 & 25 \\
\hline $\begin{array}{l}\text { An airline you respect } \\
\text { has displayed }<\text { C: } \\
\text { Displayed Service } \\
\text { Provider } \\
\text { Characteristics>. }\end{array}$ & $\begin{array}{l}\text { partial transparency, } \\
\text { by presenting self- } \\
\text { selected components } \\
\text { of its safety record for } \\
\text { public review. }\end{array}$ & $\begin{array}{l}\text { candid transparency, } \\
\text { by presenting its } \\
\text { safety record for } \\
\text { public review and } \\
\text { displaying high- } \\
\text { profile/visible } \\
\text { investments in } \\
\text { statutory/regulatory } \\
\text { technology. }\end{array}$ & $\begin{array}{l}\text { (1) moral integrity by } \\
\text { openly presenting its } \\
\text { safety record for } \\
\text { public review and } \\
\text { resolving unsafe } \\
\text { practices; (2) } \\
\text { displaying } \\
\text { investments in up-to- } \\
\text { date technology, } \\
\text { which is evident in all } \\
\text { aspects of their } \\
\text { operations; and (3) it } \\
\text { shoulders the } \\
\text { fiduciary responsibility } \\
\text { for safe passage of its } \\
\text { passengers and has } \\
\text { demonstrated that } \\
\text { responsibility during } \\
\text { past crises with }\end{array}$ \\
\hline
\end{tabular}




\begin{tabular}{|l|l|l|l|}
\hline & & & $\begin{array}{l}\text { settlements and in the } \\
\text { way it cares for and } \\
\text { handles passengers } \\
\text { affected by a crisis. }\end{array}$ \\
\hline $\begin{array}{l}\text { If this same respected } \\
\text { airline announced a } \\
\text { <D: } \text { Ticket Price } \\
\text { Reduction> as an } \\
\text { additional incentive } \\
\text { for you to fly on their } \\
\text { new, unmanned, } \\
\text { autonomous, } \\
\text { passenger } \\
\text { airliner..........would you } \\
\text { a buy a ticket? }\end{array}$ & $15 \%$ & & \\
\hline
\end{tabular}

The Vance-2014 research was comprised of eight variables, three of which produced counter-intuitive results and one which did not produce nearly the expected, response magnitude. This research update re-examined the problem space with the remaining, four, 2014-research variables that did produce expected results, while increasing their fidelity from two levels to three levels.

An exemplar, vignette version in which these remaining, four variables are embedded at the positive (+) level is shown below. Note: the Taguchi $L_{9}$, orthogonal array (shown in Table 5. ) does not include an experimental run where all four variables are set at the positive (+) level. It is shown here to facilitate understanding and clarity of the methodological process. The embedded variables in both of the following examples are bolded for visibility. Respondents saw a $100 \%$, plain text (un-bolded) version so the variables would not necessarily be obvious.

\section{A Glimpse into the Near Future}

Society is approaching a future where all transportation systems operate under autonomous control. The most familiar to you will likely be your personal automobile, which can park itself, sense obstructions and lane keep by itself. The future air transportation systems are capable of autonomously handling extensive, previously considered crippling, mechanical malfunctions / emergencies. Additionally, the system can handle the effects of severe weather, single or multiple synchronized criminal / terrorist threats, no matter whether the threats are from on board the airliner (sabotage) or remotely transmitted to the airliner(s). The transportation system and the affected airliners operating in the system are able to absorb these significant physical and cyber disruptions with acceptable, safe, survivable workarounds and minimal-to-zero disruptions in service. 
In this future unmanned, autonomous, cargo flights have operated safely for the past 25 years.

An airline that you respect has displayed (1) moral integrity by openly presenting its safety record for public review and resolving unsafe practices; (2) displaying investments in up-to-date technology, which is evident in all aspects of their operations; and (3) that it shoulders the fiduciary responsibility for safe passage of its passengers and has demonstrated that responsibility during past crises with settlements and in the way it cares for and handles passengers affected by a crisis.

If this same respected airline announced a $\mathbf{3 5 \%}$ ticket price reduction as an additional incentive for you to fly on their new, unmanned, autonomous, passenger airliner............ would you a buy a ticket?

The vignette version in which these four variables are embedded at the negative (-) level is shown below and was designed/postulated to have a distinctly less positive influence on the respondent. This vignette version is represented by Taguchi Lg array experimental run 1 (reference Table 5.).

\section{A Glimpse into the Near Future}

Society is approaching a future where all transportation systems operate under autonomous control. The most familiar to you will likely be your personal automobile, which can park itself, sense obstructions and lane keep by itself. The future air transportation systems are capable of autonomously handling limited mechanical malfunctions. More serious mechanical malfunctions, emergencies, severe weather and rogue / terrorist actions require the direct and immediate intervention of real-time human decision making for the affected airliner(s). If handled successfully, the impact of the affected airliner(s) to the overall, safe operation of the transportation system is obvious with significant disruptions in service.

In this future unmanned, autonomous, cargo flights have operated safely for the past 2-to-5 years.

An airline that you respect has displayed partial transparency, by presenting selfselected components of its safety record for public review.

If this same respected airline announced a $\mathbf{1 5 \%}$ ticket price reduction as an additional incentive for you to fly on their new, unmanned, autonomous, passenger airliner would you a buy a ticket? 
To facilitate continuity, with the sole exception of the absence of passenger flight experience, the same demographic, qualitative sampling as done in Vance (2014) (covering age, highest education level, and vocation) was presented in this updated research as well as the identical opening and closing questions bracketing the vignette.

Amazon's Mechanical Turk (MTurk) on-line, crowd-sourcing-marketplace-survey service (https://www.mturk.com/) was contracted in Jun 2018 to solicit 1,000, age 18 or greater, U.S. respondents. Each was paid $\$ 0.25$ upon submission of a code verifying a completed survey. Somewhat curiously, 1,021 valid responses were received when only 1,000 were paid for in advance. All but two of the responses were received within a 10-hour period on May $30^{\text {th }}$, 2018; the remaining two responses were received three days later. Estimated time to complete the survey was four-to-five minutes and involved reading and agreeing to an IRB-requiredrecruitment statement, answering a single, opening question regarding the propensity of accepting autonomous, airliner travel, reading one of nine randomly presented vignettes, answering a single closing question asking again the respondent's propensity of accepting autonomous airliner travel, and finally, answering three, demographic questions (age range, highest education level, and vocation). If desired, the ability to make a comment(s) was also offered.

\section{Results and Discussion}

Figures 5, 6 and 7 display the age, highest education level, and vocation dispersions of the 1,021 respondents to the updated, current research.

The demographics of the current, updated research do not reflect those of the Vance2014 collected data. The general age of the Vance-2018 respondents is nearly a generation (defined as 25 years) younger. While well-educated, with $61 \%$ of the respondents indicating at least a four-year collegiate degree or more, this percentage is significantly less than the $85 \%$ in the 2014 data indicating the same level of education.

The vocation (profession) demographics between the 2014 and 2018 Vance data sets are also not congruent. In $2014,72 \%$ of the respondents $(1,088 / 1,506)$ associated with an Aviation and/or Math \& Science vocation, leaving $28 \%(418 / 1,506)$ as Non-Math \& Science. When the 2018 "Other" category is disregarded (because a math/science orientated was indeterminate), the 2018 ratios were essentially flipped although not with equal magnitude, now 41\% (375/906) indicated Math \& Science, and correspondingly 59\% (531/906) Non-Math \& Science. These demographic differences make comparing data sets less accurate. This reality is compounded by no demographic data with the MacSween-George data sets, a presumably heavy Math \& Science respondent pool with the Tam data and an indeterminate ratio with both the UBS and ALPA data sets. 


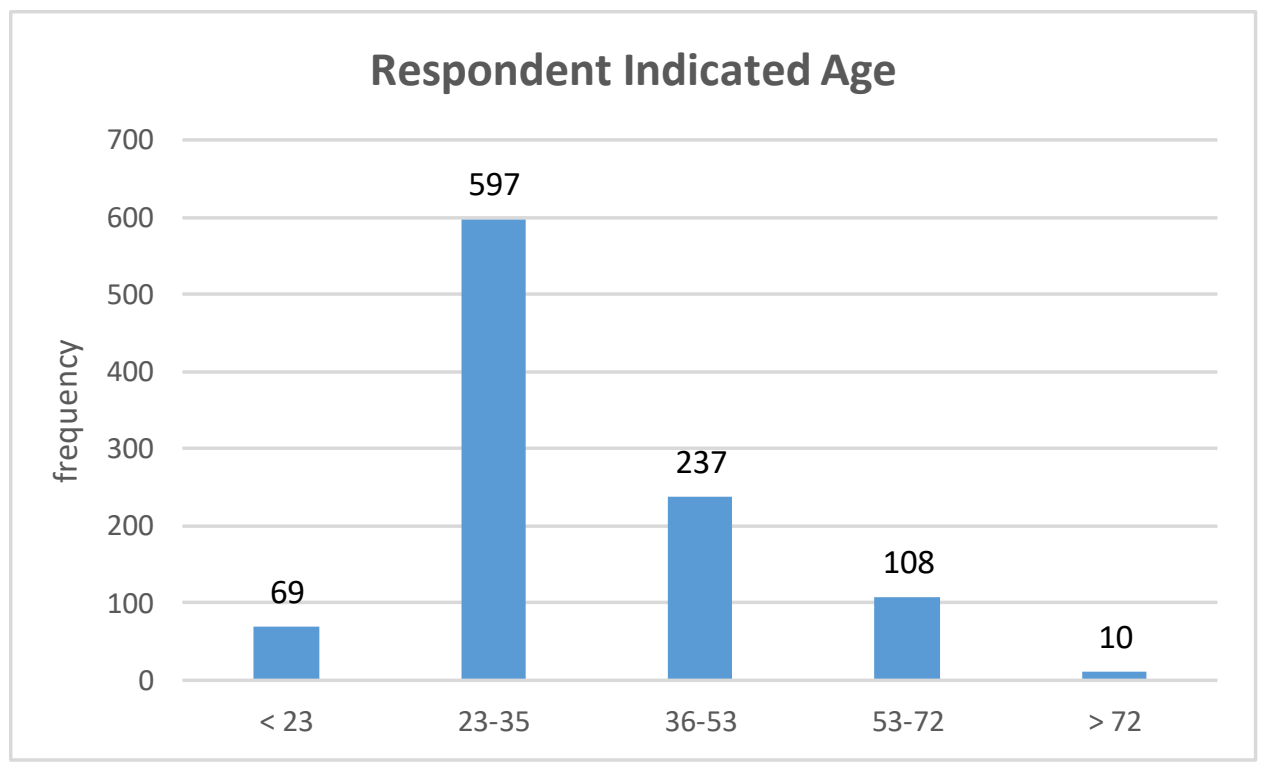

Figure 5. Respondents were queried for their age bracket at the conclusion of the Qualtrics ${ }^{\mathrm{T}}$ survey. From the received 1,021 responses, all of whom indicated age data, this dispersion shows a disproportionate skew toward younger respondents, compared to the general U.S. population.

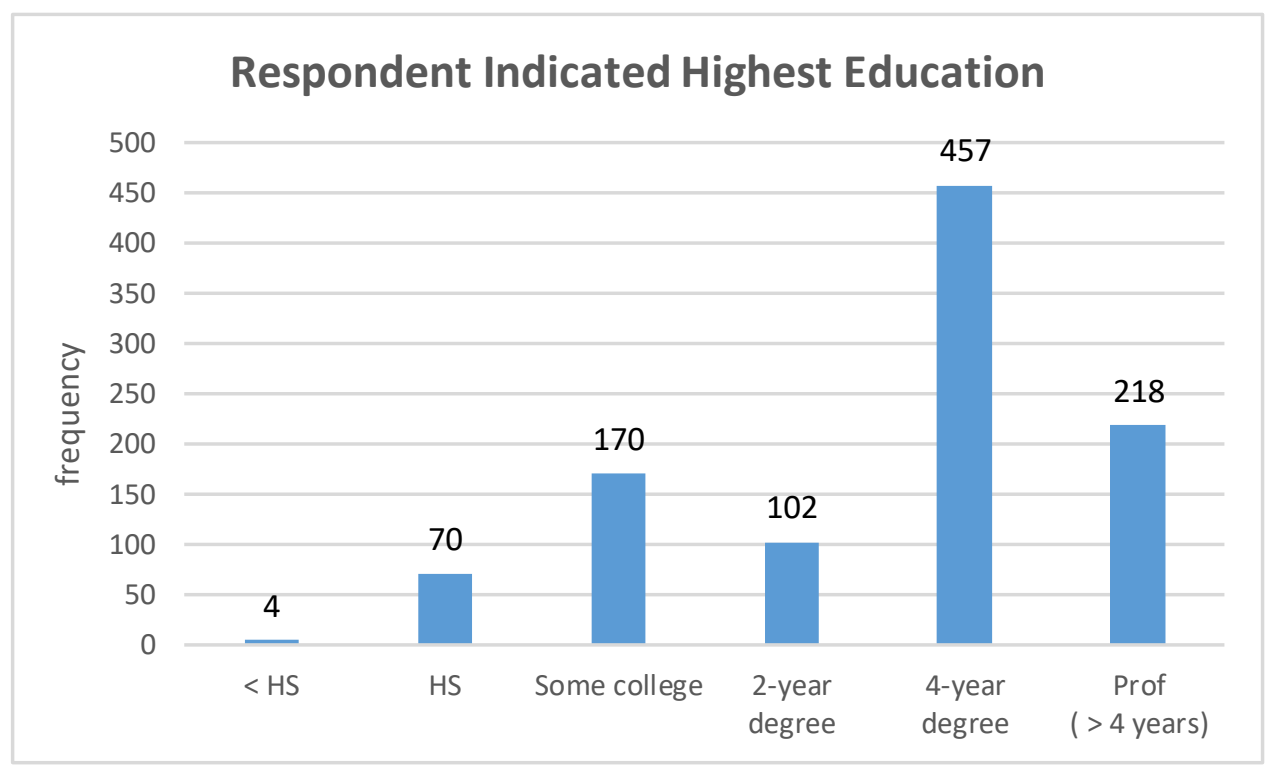

Figure 6. Consistent with the respondent age dispersion, this data shows a majority ( 675 of $1,021=66 \%$ ) of the respondents are educated at least at the collegiate, four-year degree level. All 1,021 respondents indicated an education level across one of these choices. 


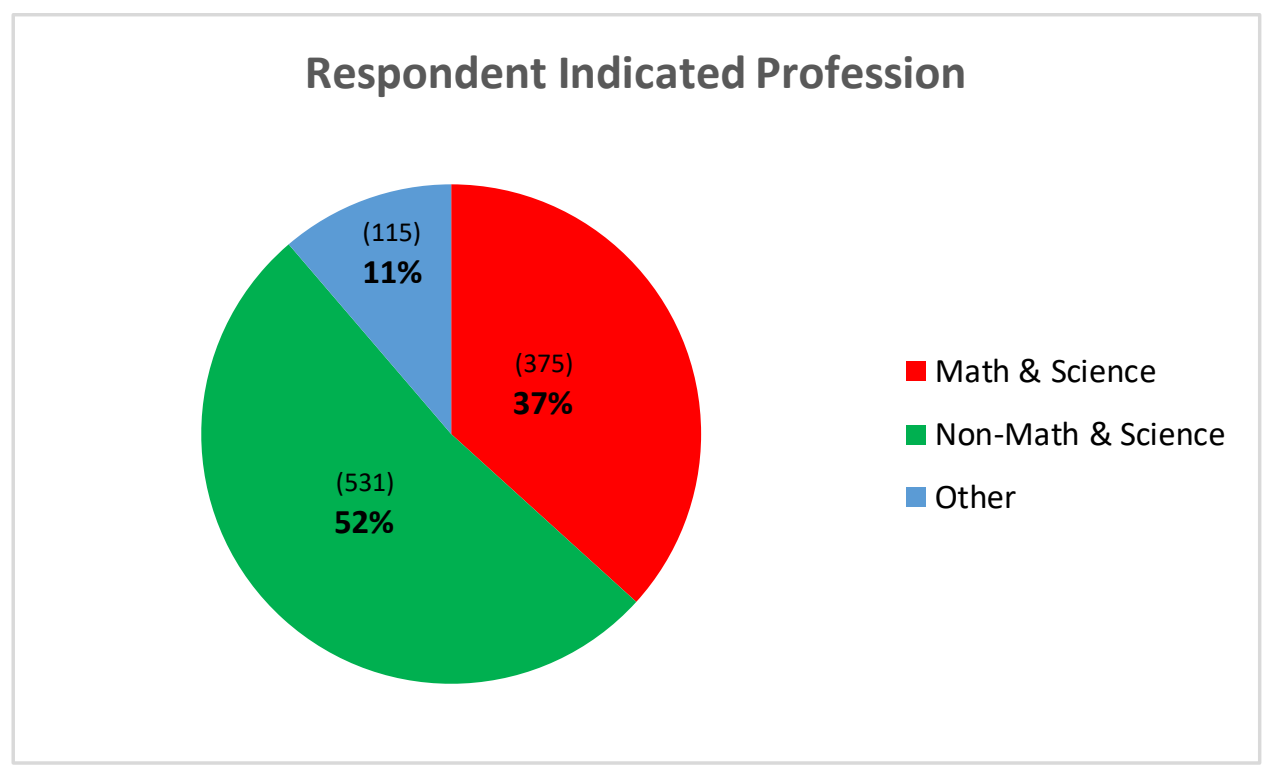

Figure 7. Respondents were also queried for the vocation (profession) in which they believe they most closely aligned. With only a handful of exceptions, respondents indicated their vocations. These three categorizations were re-coded from the raw data to more easily summarize the respondent pool. Vocations such as Engineer, IT Specialist, Researcher, and Nurse/Health Care are examples of those frequenting the "Math \& Science" category; Teacher, Cook, Manager are examples of those frequenting the "Non-Math \& Science" category; Student and Not Identified/Indicated are bookkept in the "Other" category because the math/science orientation is indeterminate.

Figure 8 shows the overall, updated, research results tallied by vignette from a Frequentist (means-based) approach and compared with results from a Bayesian ("No=Not Fly/Yes=Fly") approach. While the trends are the same, there are differences in the mathematical outputs; generally, the Bayesian approach shows higher values and more variability. Figure 8 also shows the number of each vignette $(n)$ displayed to the respondents. Rounded to the nearest whole number, the average vignette deployment, via the Qualtrics ${ }^{\mathrm{TM}}$ randomization feature was 113 instances, with a standard deviation of 2.5 (Note: $9 * 113=$ 1,017 not 1,021 , due to rounding).

From a Frequentist (means-based) approach, the average response to the opening "Would you fly on an autonomous airliner?" question was $48 \%$ with a standard deviation of $3.3 \%$ between vignettes. After reading the presented vignette, the average response to the same question rose to $52 \%$ with a standard deviation between vignettes of $4.1 \%$. The variation between vignettes in the opening and closing questions is not significant, but there are differences. Observe vignettes 2 and 9 (V2 and V9) produced the highest scores and vignettes 3 and 5 (V3 and V5) produced the lowest scores. Table 5 (which shows at which level each of the four factors were set in each vignette) does not corroborate these results as there is no discernable pattern or consistency between factor levels and response. The upper-left Frequentist view in Figure 8 does show across the nine vignettes the closing score always scored higher, on average $4 \%$ with a standard deviation of $0.8 \%$. Vignette 6 produced a unique 
result, only a $1 \%$ positive difference meaning the respondents were generally unmotivated/unencouraged/unconvinced by the vignette that the propensity of autonomous airliner travel should increase. It is, however, potentially significant the opening Frequentist question average, at $48 \%$, is the highest-yet, observed, published research comfort with autonomous airliner flight.

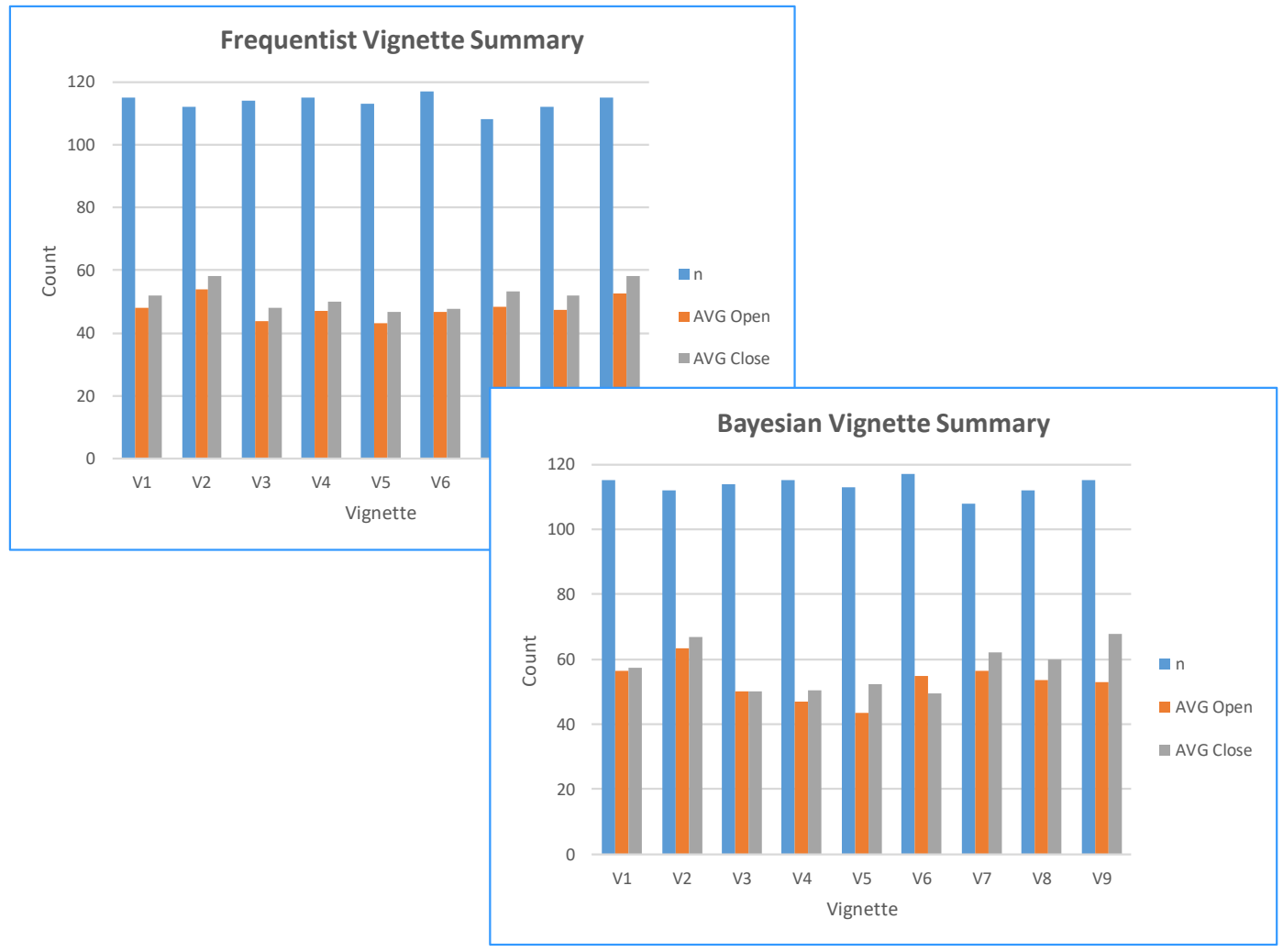

Figure 8. Compares the Frequentist (means-based) and Bayesian ("No=Not Fly/Yes=Fly") approaches and shows three data streams: a) nearly level loading of vignette by the Qualtrics ${ }^{\mathrm{TM}}$ software across the respondent pool sample sizes - $n$ (blue bars), b) average percentage of the respondent pool willing to travel on an autonomous airliner indicated on the opening question (dark orange bars), and c) average percentage of the respondent pool willing to travel on an autonomous airliner after reading the presented vignette, indicated on the closing question (grey bars).

From a Bayesian ("No=Not Fly/Yes=Fly") approach, the average response to the opening "Would you fly on an autonomous airliner?" question was $53 \%$ with a standard deviation of $5.5 \%$ between vignettes. After reading the presented vignette, the average response to the same question rose to $57 \%$ with a standard deviation between vignettes of $6.8 \%$. The variation between vignettes in the opening and closing questions is more pronounced. Observe vignettes 2 and 9 (V2 and V9) again produced the highest scores, but now vignettes 3, 4 and 5 (V3, V4 and V5) produced the lowest scores. Interestingly, Vignette 6 produced another unique result the closing score was inferior to the opening score, meaning the respondents were 
demotivated by the vignette in their willingness to travel aboard an automomous airliner.

Figure 9. focuses on the Vance-2018-opening question results and shows the raw, frequency data in bins of $10 \%$ to the left and the dichotomous Bayesian "No=Not $\mathrm{Fly} / \mathrm{Yes}=\mathrm{Fly}$ " view on the right. The Bayesian view splits the raw data into two bins: $0-50 \%=$ Not Fly, $51-100 \%=$ Fly .

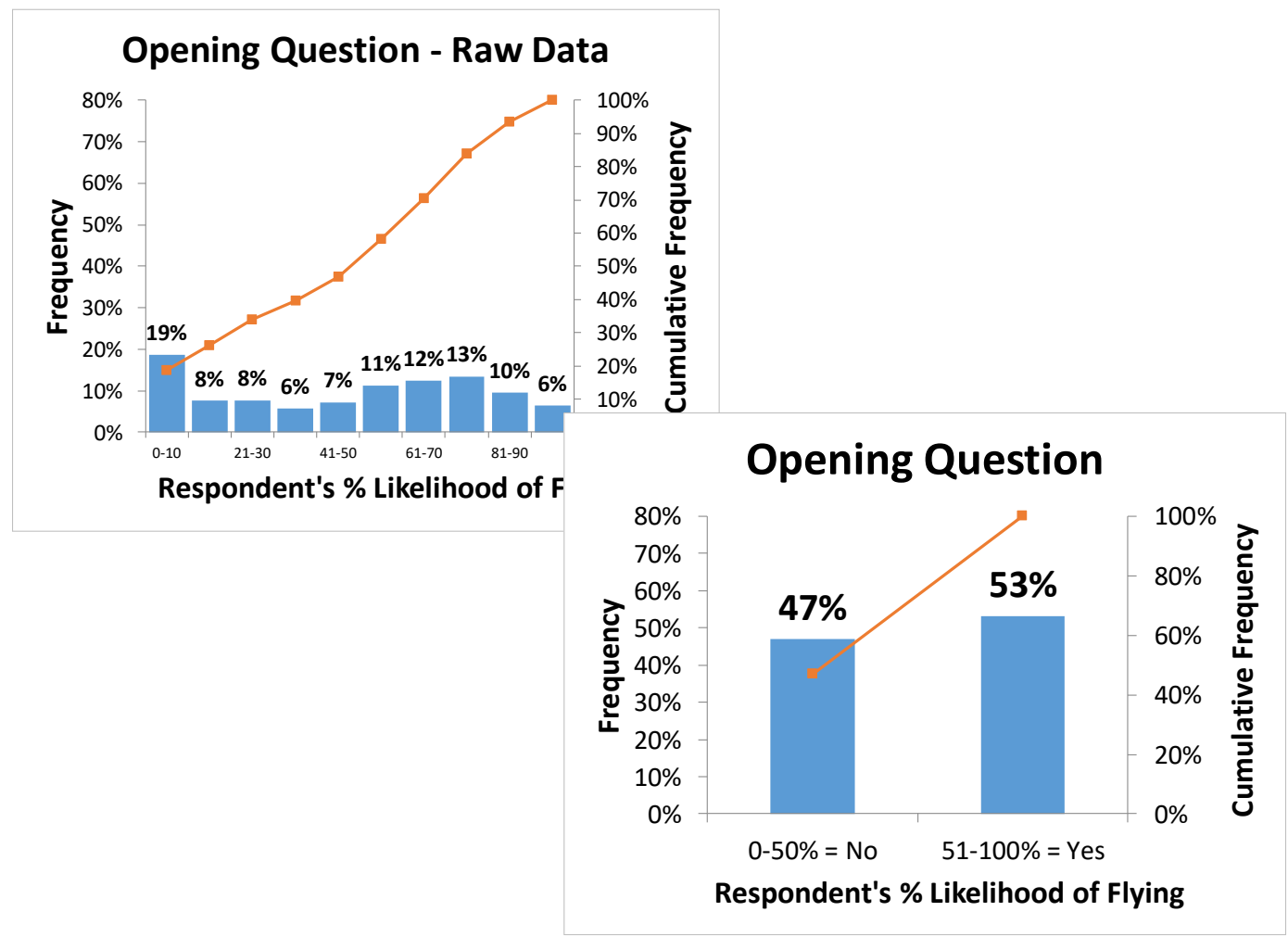

Figure 9. Shows both the Vance-2018-opening-question raw data (frequency-based) and the resulting Bayesian "No=Not Fly/Yes=Fly" view on the right. The Bayesian approach produces a difference in the numerical results; $53 \%$ of the respondents were willing to fly on an autonomous airliner before reading the presented vignette in the survey, compared with $48 \%$ in the Frequentist (means-based) calculation. The Bayesian approach also raised the closing percentage of willing, autonomous-airliner travelers from the Frequentist (means-based) value of $52 \%$ to $57 \%$.

The final results figures (Figures 10 and 11), show the influence of each of the four sampled factors (IVs) on the willingness to travel aboard an autonomous airliner from both the Frequentist (means-based) and Bayesian ("No=Not Fly/Yes=Fly") perspectives. Recall the " -1 " level represented the least-expected, influential level of the IV, the " 0 " level an intermediate level of influence, and the " +1 " level was expected to be the most influential level of the IV. Both figures are plotted on a constant vertical scale so they can more easily be compared. Figure 10 shows the factors' influence on 
the opening question, while Figure 11 shows the influence on the closing question. Using the 3-level factor approach shows in all cases the behavior of the factors' influence is not linear. The behavior of the factors did not produce the expected positive results; if they had, each factor's influence would be increasing, evidenced by a positive slope moving from left (-) to right (+). The trends for all factors are independent of the opening or closing question.

When comparing the least-expected influential level (-) with the most-expected influential level (+):

Factor A) System Response to Interruptions does show an overall (small) positive influence but with a significantly lower influence at the intermediate (0) level.

Factor B) Years of Autonomous Cargo Operations has the shallowest curvature, and curiously peaks with the intermediate (0) level. It could generally be concluded this factor was of overall, minimal influence no matter at what level it was set and may mean the respondents were not sensitive/did not care how many years of autonomous cargo operations preceded autonomous passenger service.

Factor C) Service Provider Characteristics, was the most influential factor in the Vance-2014 research and is confounded here with the positive level $(+)$, resulting in an inferior influence compared with either the intermediate (0), or even the negative level $(-)$. This is disturbing as the wording of this previously influential factor was unmodified in the current, updated, 2018 research.

Factor D) Ticket Price Reduction demonstrates the same behavior as Factor $\mathrm{C}$ ) but of greater magnitude; i.e. the positive $(+)$ level is inferior in influence to either the intermediate (0) or negative level (-). The Factor $D$ data swings are not as significant as Factor C; suggesting a service provider may not need to incentivize autonomous-airliner travel with a price reduction beyond $15 \%$. At first blush, this is a counter-intuitive result unless the perception is that more aggressive price reductions are an implicit admission of less safety. 


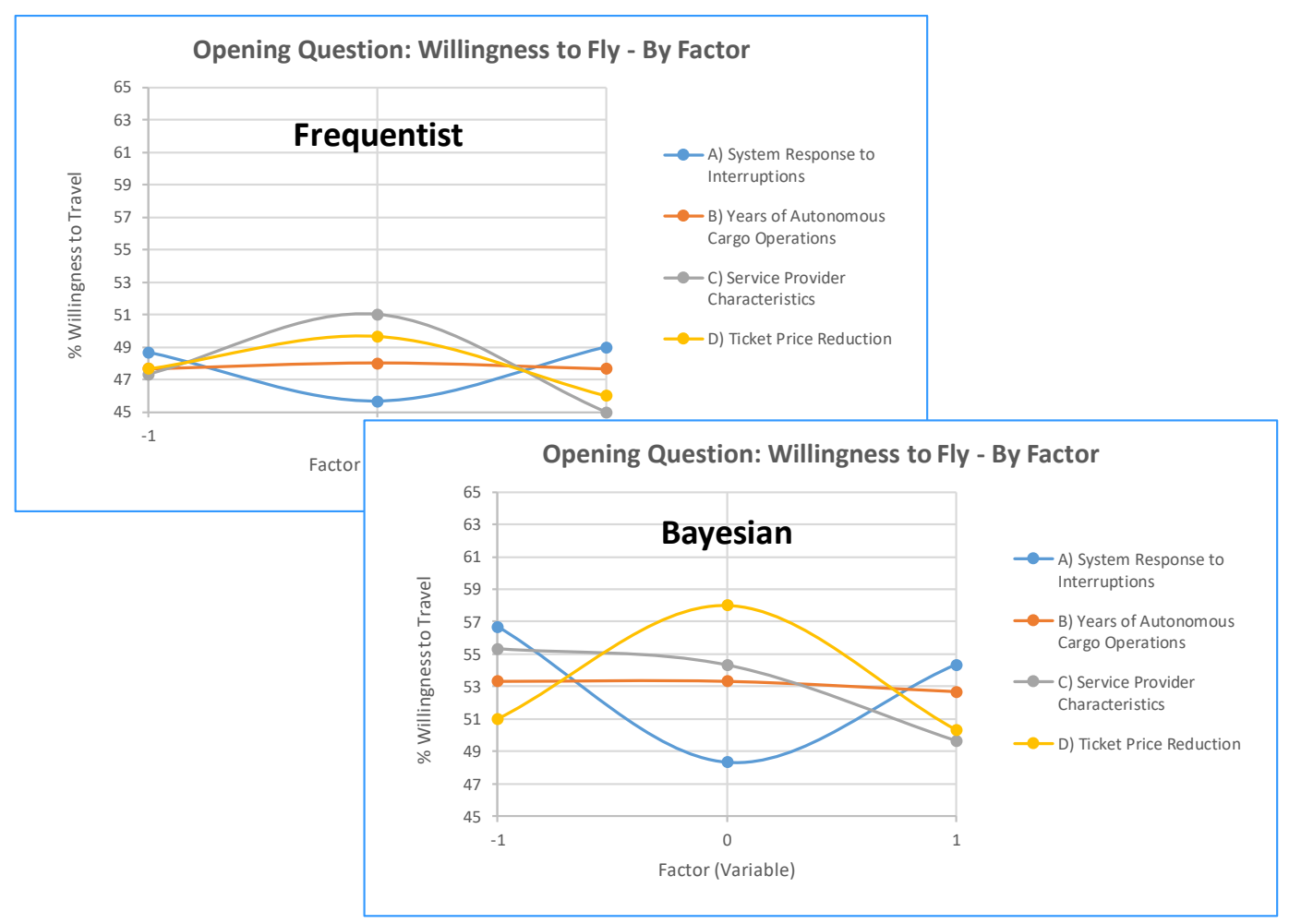

Figure 10. Shows the influence of each of the four research factors (IVs) on the average respondent's willingness to travel aboard an autonomous airliner in the opening survey question (before the presentation/influence of the vignette). The average of all 12 data points in the Frequentist plot $=48 \%$; the Bayesian plot average of all 12 data points $=53 \%$. In both plots, the intermediate level $(0)$ of factors $(B$ and $D)$ show the highest influence, while the intermediate level (0) of factor A shows the least influence. Factor C's influence changes between the methods from peaking at the intermediate level $(0)$ in the Frequentist method to a continous decline from the negative level $(-1)$ in the Bayesian method. 


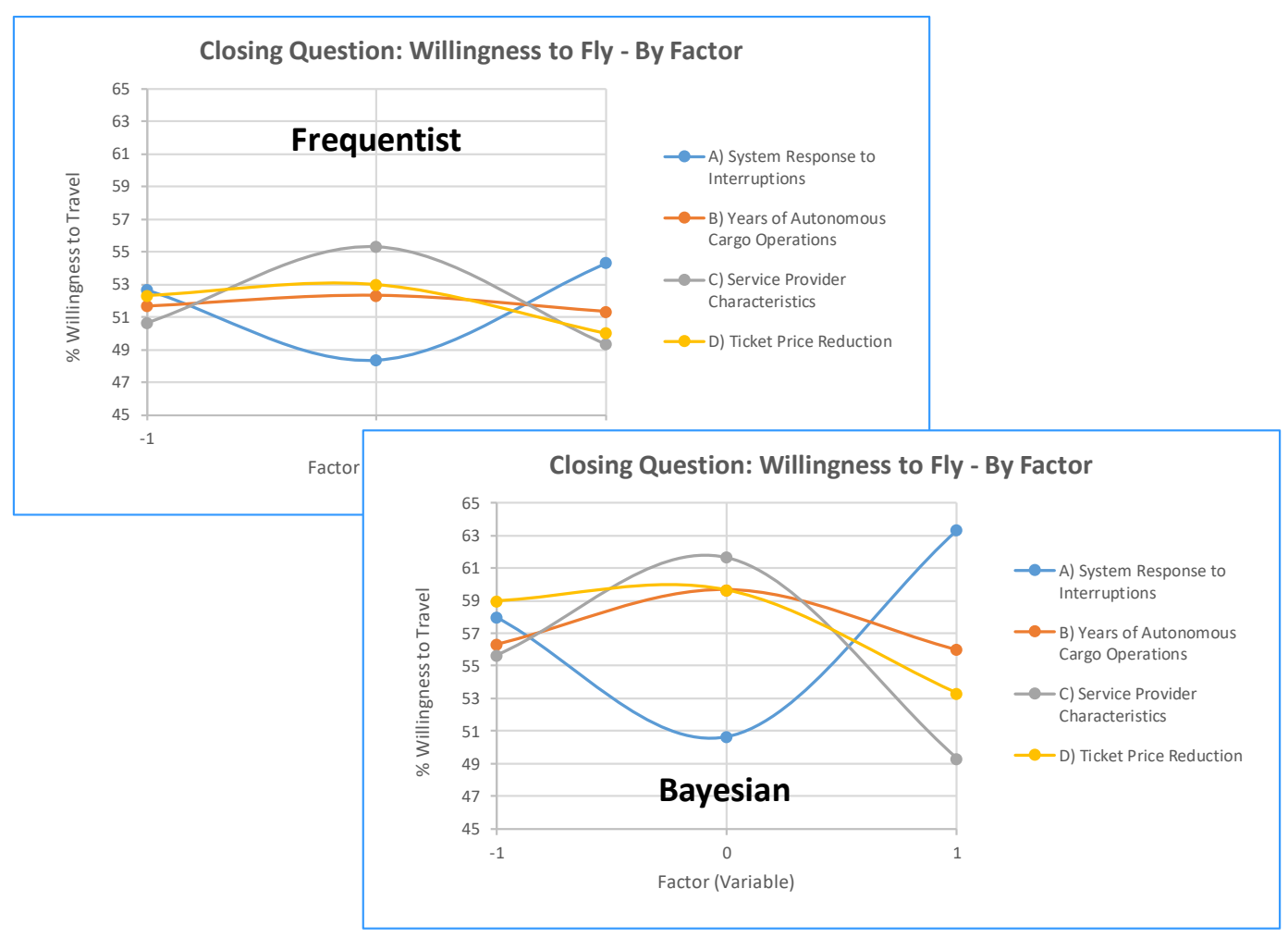

Figure 11. Correspondingly shows the influence of each of the four research factors (IVs) on the average respondent's willingness to travel aboard an autonomous-airliner in the closing survey question (after the presentation/influence of the vignette). The average of all 12 data points has now increased across the Frequentist and Bayesian plots, 52\% and 57\% respectively. Compared with the opening question, a very similar factor influence pattern is evident in the closingquestion results. Obseve all four curves have also shifted up 4 percetage points; with the exception of factor $\mathrm{C}$ ) in the Bayesian plot where its maximum inflection is amplified.

Figure 12 plots the factor influences in the same format (maximum difference between positive (+) and negative (-) level and on the same vertical scale) as was done in the Vance2014-published research and shown in this paper in Figure 4. This view masks the intermediate behavior of the 3-level factors and is included for comparison only. The upper figure is the Frequentist view. The lower figure, the Bayesian view, is directly comparable with the Vance2014-Bayesian view. As was shown previously, the Bayesian approach accentuates and amplifies the trends evident in the Frequentist approach. 


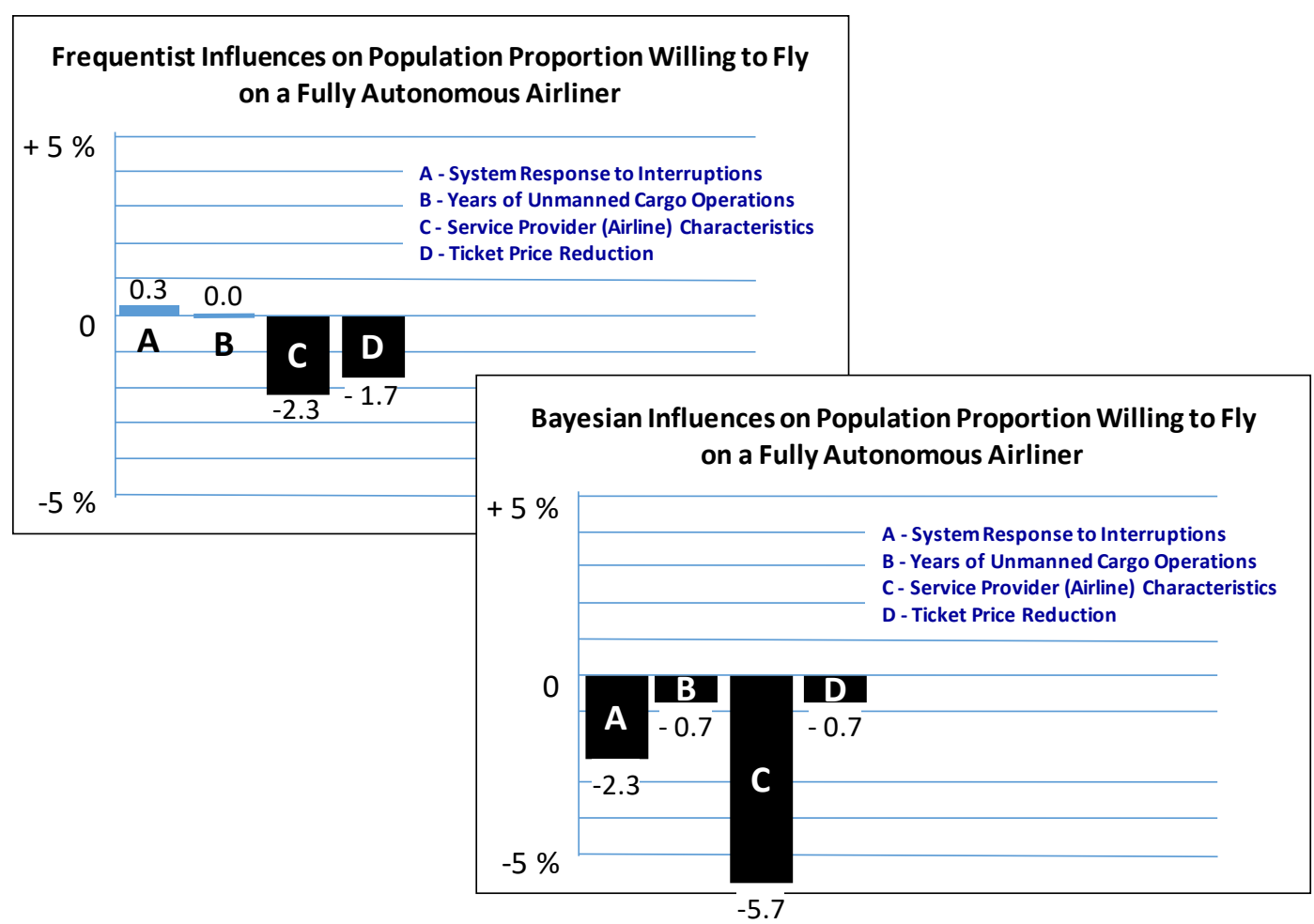

Figure 12. Shows the overall magnitude factor influence in the Vance-2018 research when restricted to a comparison between only the negative (-) and positive (+) level for both the Frequentist and Bayesian approaches. From this perspective, when the Bayesian approach is compared to Figure 4 (the Vance-2014 research), the factors are less influential and, in the case of factor $\mathrm{C}$, have flipped in influence. The positive level (+) of each factor had a negative influence on the decision to fly aboard an autonomous airliner.

The overall conclusion regarding the factors' influence on respondents is difficult/impossible to qualify, and this is a disapointment as apparently the options may have been ineffectively/confusingly worded, or they possibly may no longer matter as much as they did five years ago. Ultimately, the positive (+) level of the factors did not significantly influence respondents, thus the factors, as defined in the 2018 research, are difficult to reliably credit with the decision to travel on an autonomous airliner. As defined, the intermediate ( 0 ) and positive (+) levels of the factors appear to have dissuaded respondents' decision to travel on an autonomous airliner. Given that the closing question values rose, despite the apparent negative influence of the factors individually, the simple presence of the vignette describing facets of autonomous airliner travel appears to have been influential.

Almost all the respondents added comments at the conclusion of their survey; about half of the comments had material value - the remainder were in the 'None/no comment' category. Only a few comments were derogatory, compared with the many that were complimentary of the vignette approach and the provoking study of an "inevitable transportation future". The overwhelmingly consistent comment was a plea for more 
explanatory data particularly regarding the safety and statistics of the overall operation of UAS and autonomous cargo flights. The ironic aspect of these pleas is the autonomous-cargo-safety record-information was present as an IV in the Vance-2013 survey but was purposefully removed by the authors in the 2018 survey because it was deemed uninfluential and duplicative.

Another repeated comment was reading the vignette demotivated respondents. Comments such as, "Felt braver at beginning of survey than after reading short article", "I was discouraged by the lack of information", and "At first, I was all for it but then I thought and there are so many factors involved and so many things that can go wrong. This is something I would have to think over and read some more about" are indicative of other persons with a similar view. When examined with the Bayesian approach, the consistent negative influence of the positive (+) IV's level on the opening question (shown in Figures. 10 and 12), the generally weak overall increase in the willingness to travel aboard an autonomous airliner after reading all versions of the vignettes, and the reduction in willingness to travel as evidence by the respondents in Vignette six (see Figure. 8) also attest to the inability of the vignettes to convince or motivate as strongly as had been evidenced in the previous Vance-2013 data.

Understanding this research was not undertaken to motivate or convince travel aboard an autonomous airliner but rather to assess the impact of the IV's ability to influence the choice to travel, it is unfortunate the brevity of the vignettes may have hindered the ability to fully assess the four evaluated IVs' ability to influence travel. However, the research has revealed the respondents reacted to the IVs and will demand more information before committing to travel.

When the Bayesian-binary- "Not Fly/Fly" approach is applied to the progression of MacSween-George-2003, Vance-2013 and Vance-2018 data, Figure 13 results. The upper, leftmost plot shows the MacSween-George-2003 results and is the "prior" for the first, Bayesian update. The middle plot incorporates the Vance-2013-opening-question data as the "posterior", completing the first, Bayesian update, raising the MacSween-George $\mu=10.5$ $(10.5 \%)$ to a $\mu=27.1$ (27.1\%). This intermediate data is used as the "prior" for the second, Bayesian update, with the Vance-2018-opening-question Bayesian data as the "posterior", completing the second-Bayesian update where the mean shifts to a $\mu=36.9$ (36.9\%). This value represents the historical influence of MacSween-George-2003 and Vance-2013 data on the Vance-2018 data and is lower that the stand-alone, Vance-2018-opening-question-Frequentist percentage of $48 \%$, or the opening-Bayesianpercentage of $53 \%$, because it incorporates (tempers) the current 2018 data with two historical precedents. 


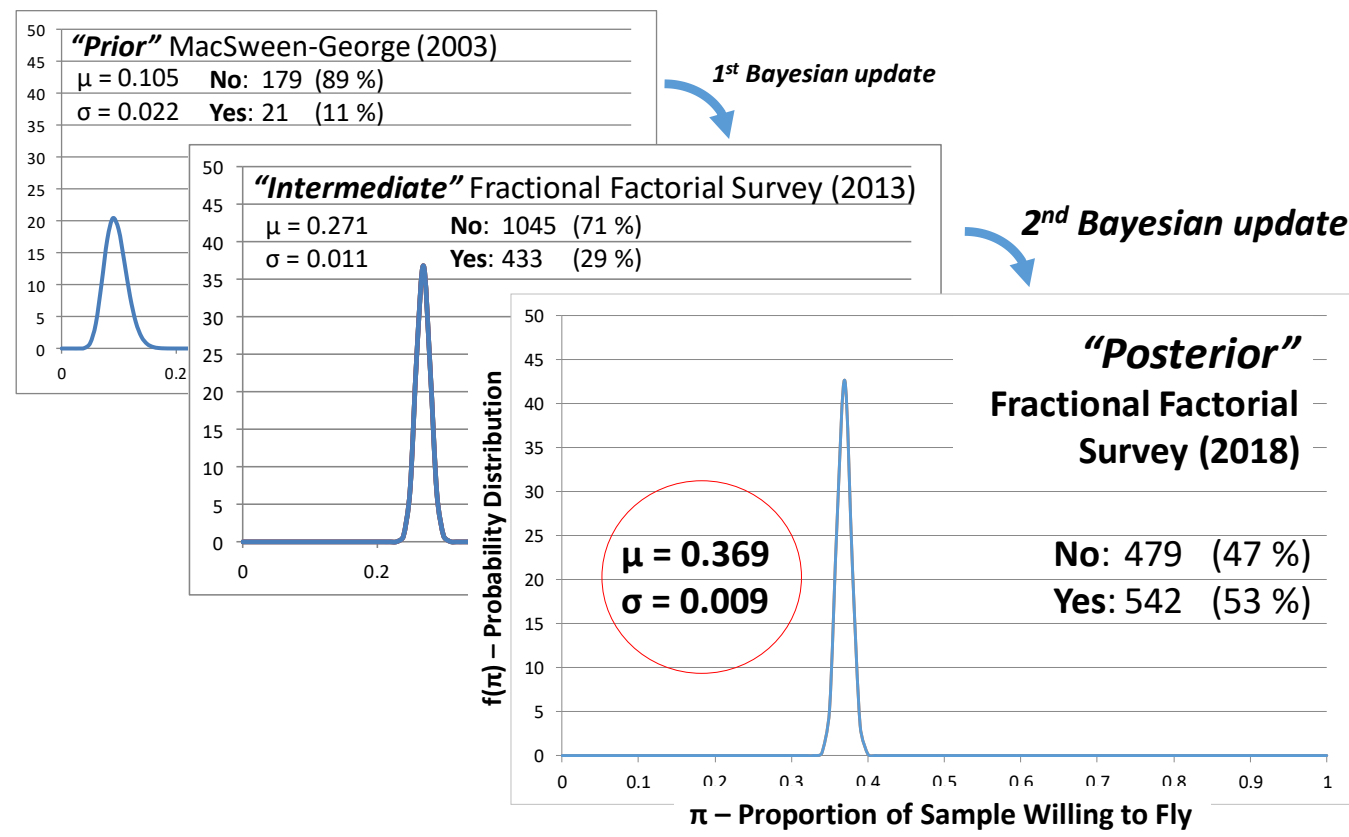

Figure 13. Illustrates a 16-year progression across three studies. Notice the mean value, the willingness to fly aboard an autonomous airliner, represented by the hump in the binomial distribution, continues its progression toward $1.0(100 \%)$ and the standard deviation continues to shrink, evidenced by the increasing height and tightening of the distributions.

When the results of this 2018-updated research are integrated with the longitudinal trending shown in Figure 2, Figure 14 results. Before examining Figure 14, it is important to qualify that the population samples and demographics across the seven research studies only share one, defensible commonalty - all are U.S. respondents; however, the samples do share other valuable similarities. Table 7 illustrates characteristics of the now seven studies. The primary area the samples may be different is in the vocational backgrounds of the respondents.

Table 7. Shows, chronologically, from left to right the seven, referenced, published studies directly dealing with the willingness to travel aboard an autonomous airliner. While the demographics are not identical, they share important commonalties: universally all are samples of U.S. adults, four of the seven samples are nearly identical, larger respondent sizes, and the remaining three are similar, smaller sizes.

\begin{tabular}{|c|c|c|c|c|c|c|c|}
\hline \multirow[b]{2}{*}{ Study } & \multirow{2}{*}{\multicolumn{2}{|c|}{$\begin{array}{cc}\text { MacSween- } & \text { MacSween- } \\
\text { George } & \text { George } \\
\text { (IEEE) } & \text { (AIAA) }\end{array}$}} & \multirow[b]{2}{*}{ Vance } & \multirow[b]{2}{*}{ Tam } & \multirow[b]{2}{*}{ USB } & \multirow[b]{2}{*}{ ALPA } & \multirow[b]{2}{*}{ Vance } \\
\hline & & & & & & & \\
\hline Year Data Collected & 2003 & 2003 & 2013 & 2011 & 2017 & 2018 & 2018 \\
\hline$n$ & 120 & 200 & 1,506 & 158 & 1,507 & 1,109 & 1,021 \\
\hline Respondent Location & U.S. & U.S. & U.S. & U.S. & U.S. & U.S. & U.S. \\
\hline $\begin{array}{r}\text { Vocational } \\
\text { Demographics }\end{array}$ & $\begin{array}{l}\text { Aerospace } \\
\text { industry }\end{array}$ & $\begin{array}{c}\text { Primarily } \\
\text { international } \\
\text { travelers at LAX }\end{array}$ & $\begin{array}{l}\text { 72\% Aviation, } \\
\text { and/or Math \& } \\
\text { Science }\end{array}$ & $\begin{array}{l}\text { Aviation } \\
\text { professional } \\
\text { society / } \\
\text { University }\end{array}$ & $\begin{array}{c}\text { Airline } \\
\text { passengers }\end{array}$ & $\begin{array}{l}\text { American } \\
\text { citizens }\end{array}$ & $\begin{array}{l}41 \% \text { Math \& } \\
\text { Science }\end{array}$ \\
\hline
\end{tabular}




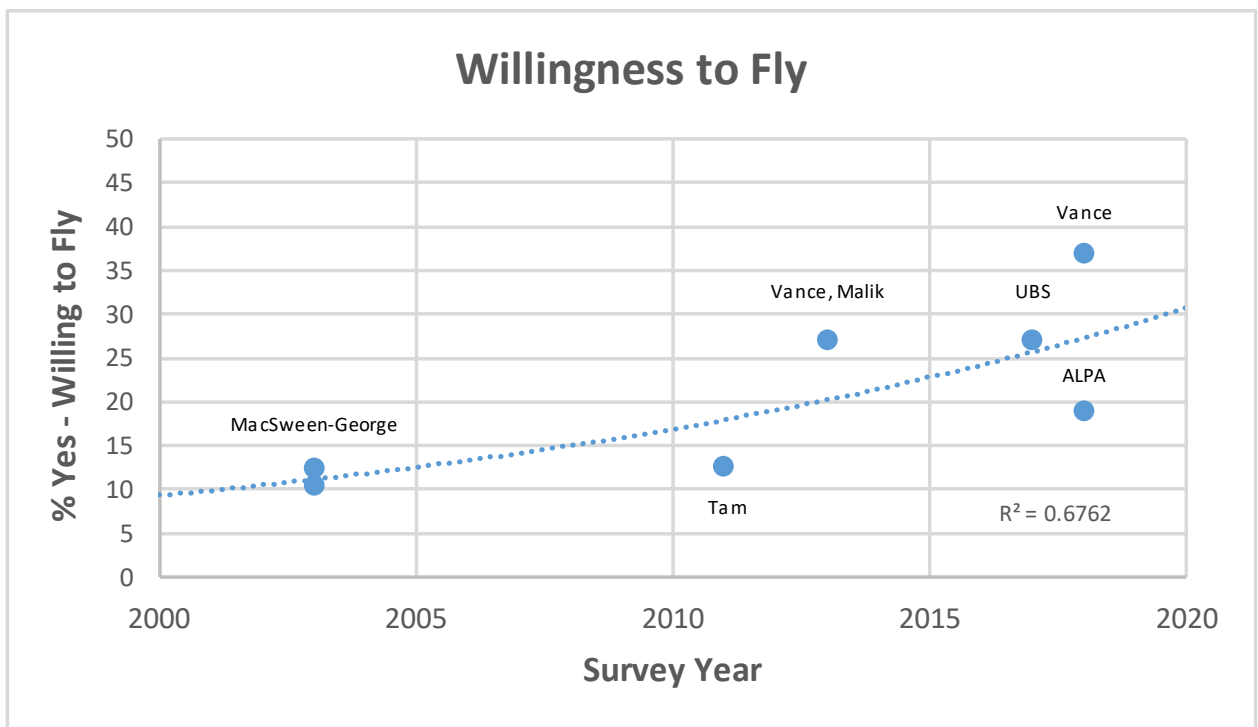

Figure 14. The addition of the Vance-2018-updated research shifts the exponential trend line up and raises the $R^{2}$ value to 0.6762 . Notice the 2018-opening-question-Bayesian ("Not Fly=No/Fly=Yes") value $(36.9 \%)$ is displayed, not the higher Frequentist-based value nor either of the closing values. The most conservative opening-question value is the best representation of an unbiased response. Recall the closing-question values were influenced by the respondent's exposure to the vignette which they were presented.

This trending data suggests in 2019, 30\% of respondents are willing to travel on an autonomous airliner - now. If the trend data were extrapolated into the future, the $50 \%$ earlyadopter threshold would be reached around 2030. If true, this is an amazingly, intriguing, provocative statement and would suggest the public's willingness to accept autonomous airliner travel would have reached an early adopter marketing level much sooner than may have been previously anticipated.

The Vance-2018 research has thus produced three perspectives on the percentage of respondents willing to travel aboard and autonomous airliner a) opening-question-Frequency (means-based) response of $48 \%, b$ ) opening-question-Bayesian-based response of $53 \%$, and c) a Bayesian-updated, historical perspective incorporating MacSween-George-2003 and Vance2013 data with the Vance-2018 data, producing a response of $36.9 \%$

The historical, Bayesian-updated data compares favorably with the longitudinal trending data shown in Figure 14 and is thus potentially more credible than using the Vance-2018 data alone.

Finally, to address the first posed research question (RQ1) and its associated hypothesis $\left(H_{a} 1\right)$, it is not surprising, with a large-means difference and large-sample sizes, a Two-Sample ZTest for means confirmed at $\alpha=0.01$, the 2018 Bayesian-based sample (at $36.9 \%$ ) is statistically significant compared with the Bayesian-2013-intermediate results of $27.1 \%$, thus accept $\mathrm{H}_{a} 1-$ 
There is a statistically significant difference in the general population's valuation of travel aboard an autonomous airliner in 2018 than previously reported for the predominantly aviation, science and technology sample taken in Oct 2013.

To address the second posed research question (RQ2), the overall 2018 research impact of the four factors influence in the respondent's decision to travel aboard an autonomous airliner is significantly less pronounced than in the 2013 research. And, it is potentially significant that the positive (+) IV levels were frequently producing inferior response acceptance, measured with either the Frequentist or Bayesian methods, to the intermediate (0) or negaitve (-) levels.

\section{Conclusion}

The notion of autonomous airliners is complicated, technically/regulatory/security intense and apparently more sensitive/difficult to accept for many middle-aged and older passengers. This may simply be a reflection of the inability of humans to trust their lives, thus abdicating this responsibility, to the integrity of a programmed machine.

The four, researched factors' influence in the decision to travel aboard an autonomous airliner, while seeming clearer in the Vance-2013 data, appear muddied and counter-intuitive in the Vance-2018 data. From a quality-of-research perspective, this indeterminate result was unexpected but lack of data, is data - these four factors may no longer matter as much as they did? The one, overall, trending conclusion which can be made from this updated research is we, as a U.S. traveling society, appear to be continuing the march to accept autonomy in airline travel. 


\section{References}

ALPA. (2018). New survey shows Americans strongly opposed to removing pilots from the cockpit, alpa.org. Retrieved from http://www.alpa.org/news-and-events/newsroom/2018-07-31-survey-shows-americans-oppose-removing-pilots-from-cockpit

Bachman, J. (2018). Single pilot operations for air cargo-a test for autonomous flying, Insurance Journal.com.docx. Retrieved from https://www.insurancejournal.com/news/national/2018/10/11/504089.htm

Batchelor, T. (2018). Single-pilot passenger planes could soon take to the skies, The Independent.docx. Retrieved from https://www.independent.co.uk/travel/news-andadvice/single-pilot-plane-boeing-autonomous-jet-technology-cockpit-a8506301.html

Bellamy, W. (2017). Boeing VP talks future of passenger plane autonomy, Aviationtoday.com. Retrieved from https://www.aviationtoday.com/2017/06/22/boeing-vp-talks-futurepassenger-plane-autonomy/

Bostock, W. (2019). Airbus says it has the technology to fly planes with no pilots, Business Insider.com. Retrieved from https://www.businessinsider.com/airbus-says-pilotlessflights-ready-when-you-are-2019-6

Britt, S.H., Nelson, V. (1976). The marketing importance of the "just noticeable difference", Business Horizons. 19: 38-40.:doi:10.1016/0007-6813(76)90063-X

Bryan, V. (2018). Two become one; Planemakers work on tech to cut pilot numbers, Reuters.com. Retrieved from https://uk.reuters.com/article/uk-britain-airshow-singlepilot/two-become-one-planemakers-work-on-tech-to-cut-pilot-numbersidUKKBN1K829L

Castle, J., et.al. (2017). Flying solo: how far are we down the path towards pilotless planes? UBS Global Research. Retrieved from: http://nzz-files-prod.s3-website-eu-west1.amazonaws.com/2017/8/7/93872795-5ab9-4f94-bb3a-f6ed38c6b886.pdf

CB Insights. (2016). 33 Corporations working on autonomous vehicles, $C B$ Insights. Retrieved from https://www.cbinsights.com/blog/autonomous-driverless-vehicles-corporationslist/

Clayton, K., Hughes, J., Rice, S., Trafimow, D. (2009). The automated cockpit: a comparison of attitudes towards human and automated pilots, Transportation Research Part F: Traffic Psychology and Behavior, 12(5), 428-439. 
Coren, M.J. (2019). What the autonomous vehicles industry should learn from the Boeing 737 Max crisis, qz.com. Retrieved from https://qz.com/1595490/what-the-737-max-crisiscan-teach-the-autonomous-vehicles-industry/

Doyle, A. (2010). Embraer reveals vision for single-pilot airliners. Flight Global. Retrieved from: https://www.flightglobal.com/news/articles/embraer-reveals-vision-for-single-pilotairliners-343348/

CNBC. (2017). Boeing studies pilotless planes as it ponders next jetliner. Retrieved from https://www.cnbc.com/2017/06/08/boeing-studies-pilotless-planes-as-it-ponders-nextjetliner.html

Epley, N., Heafner, J., Waytz, A. (2014). The mind in the machine: anthropomorphism increases trust in an autonomous vehicle. Retrieved from http://web.b.ebscohost.com/ehost/detail/detail?vid=12\&sid=6b0fdc99-cff9-4236-95f52c3f0117aecf\%40sessionmgr111\&hid=110\&bdata=JnNpdGU9ZWhvc3QtbGI2ZQ\%3d\%3d $\# \mathrm{db}=\mathrm{a} 9 \mathrm{~h} \& \mathrm{AN}=94642872$

Fast-Forwarding to a Future of On-Demand Urban Air Transportation. (2016). Uber Elevate. Retrieved from https://www.uber.com/elevate.pdf

Galford, C. (2018). ALPA survey shows public criticism of automated aircraft replacing pilots, Transportationtodaynews.com. Retrieved from https://transportationtodaynews.com/news/10202-alpa-survey-shows-public-criticismof-automated-aircraft-replacing-pilots/

Graves, R. (2018). This is your captain speaking-will computers learn to fly well enough before pilots forget how? Retrieved from http://www.robertgraves.com/2017/11/willcomputers-learn-to-fly-well-enough.html

Hollinger, P. (2016). Pilotless planes take to skies over England. Financial Times. Retrieved from: https://www.ft.com/content/8c8325d6-b89e-11e6-961e-a1acd97f622d

IATA. (2010). IATA economic briefing: airline fuel and labor cost share. Retrieved from: https://www.iata.org/whatwedo/Documents/economics/Airline_Labour_Cost_Share_F eb2010.pdf

Isidore, C. (2015). Would pilotless planes make sense? Retrieved from http://money.cnn.com/2015/03/27/news/companies/pilotless-passenger-planes/

Isops. (2018). Few would be comfortable with flying on pilotless airliners, Ispos.com. Retrieved from https://www.ipsos.com/en-us/news-polls/Few-Would-be-Comfortable-withFlying-on-Pilotless-Airliners 
Kelly, M. (2017). With the rise of autonomous vehicles, hackers pose a serious new threat. UVA Today. Retrieved from: https://www.news.virginia.edu/content/rise-autonomousvehicles-hackers-pose-serious-new-threat

Levin, A. (2018). Lion air crash demonstrates unintended consequences of cockpit automation, Insurance Journal.com. Retrieved from https://www.insurancejournal.com/news/international/2018/11/30/510682.htm

Le Tallec, C. Joulia, A., Harel, M. (2013). Personal plane automated operations strategy. Presented at Aviation technology, integration, and operations conference, AIAA aviation 2013, Los Angeles, California. AIAA

Little, R. (2019). Automation of planes began 9 years after the wright bros took flight, History.com. Retrieved from https://www.history.com/news/plane-automationautopilot-flight-302-610

Ludwick, R., Zeller, R.A. (2001). Factorial survey-an experimental method to replicate real world problems, Nursing Research, Volume 50(2), March/April 2001, pp. 129-133. Retrieved from http://hy2ju6vj2n.scholar.serialssolutions.com/?sid=google\&auinit=R\&aulast=Ludwick\& atitle=The+factorial+survey:+an+experimental+method+to+replicate+real+world+proble ms\&title=Nursing+research+\%28New+York\%29\&volume=50\&issue=2\&date=2001\&spag $e=129 \& i s s n=0029-6562$

MacDonald, J. (2008). 14 useless insurance policies. Bankrate. Retrieved from http://www.bankrate.com/finance/insurance/14-useless-insurance-policies-1.aspx

MacSween-George, S.L. (2003). Will the public accept UAVs for cargo and passenger transportation? IEEE Aerospace Conference Proceedings, 1, 357- 367.

MacSween-George, S.L. (2003). A public opinion survey - unmanned aerial vehicles for cargo, commercial, and passenger transportation, 2nd AIAA "Unmanned Unlimited" Systems, Technologies, and Operations - Aero Pac, AIAA 2003-6519.

Markoff, J. (2015). Planes without pilots. Retrieved from http://www.nytimes.com/2015/04/07/science/planes-without-pilots.html

Marks, P. (2014). What it's like to fly passenger planes from the ground? Retrieved from https://www.newscientist.com/article/dn26026-what-its-like-to-fly-passenger-planesfrom-the-ground/

Moskvitch, K. (2016). Would you fly in a pilotless airliner? BBC. Retrieved from: http://www.bbc.com/future/story/20160912-would-you-fly-in-a-pilotless-airliner 
Mutuel, L. (2013). What makes unmanned aircraft systems so complex to certify for civil operations? Presented at Aviation technology, integration, and operations conference (ATIO 2013): AIAA aviation 2013, Los Angeles, California. AIAA

National Institue of Standards and Technology (NIST). (2108). Engineering Statistics Handbook, Ch 5 Process Improvement. Retrieved from http://www.itl.nist.gov/div898/handbook/pri/section3/pri33a.htm

Negroni, C. (2019). What people don't get about why planes crash, Vox.com. Retrieved from https://www.vox.com/first-person/2019/4/22/18511069/boeing-737-max-crash-plane

Owens, B. (2017). Will passengers ever fly on pilotless planes? Insidescience.com. Retrieved from https://www.insidescience.org/news/will-passengers-ever-fly-pilotless-planes

Phillips, J. (2016). The Ehang 184 is a single-passenger drone that transports people (yes, people) at 11,000 feet. Retrieved from http://www.macworld.com/article/3019704/consumer-electronics/the-ehang-184-is-asingle-passenger-drone-that-transports-people-yes-people-at-11-000feet.html\#tk.rss_all

Pilotless Planes. (2003). Swedish Press, 74, 15. Retrieved from https://search-proquestcom.argo.library.okstate.edu/docview/217803108?accountid=4117

Rankin, W. (2007). MEDA investigation process, Boeing.com/COMMERCIAL/AEROMAGAZINE Retrieved from: http://www.boeing.com/commercial/aeromagazine/articles/qtr_2_07/AERO_Q207_arti cle3.pdf

Reed, T. (2018). Airline pilots battle "attack on safety" from single pilot cargo aircraft study, Forbes.com. Retrieved from https://www.forbes.com/sites/tedreed/2018/06/06/airline-pilots-battle-attack-onsafety-from-single-pilot-cargo-aircraft-study/\#1e7460276bdc

Rice, S., et.al. (2014). Passengers from India and the United States have differential opinions about autonomous auto-pilots for commercial flights. International Journal of Aviation, Aeronautics, and Aerospace, 1(1). https://doi.org/10.15394/ijaaa.2014.1004

Rice, S. (2019). Would you fly on a plane without a human pilot? Forbes.com. Retrieved from https://www.forbes.com/sites/stephenrice1/2019/01/07/would-you-fly-on-a-planewithout-a-human-pilot/\#3daa54bd2518

Rice, S., Winter, S. (2019). Despite consumer worries, the future of aviation will be more automated, theconversation.com. Retrieved from https://theconversation.com/despiteconsumer-worries-the-future-of-aviation-will-be-more-automated-113807 
Ridley, M. (2014). This isn't your captain speaking. It's a robot; irrational fears about pilotless planes must eventually give way to the evidence that they are better and safer. Times [London, England] 1 Dec. 2014: 29. Business Insights: Essentials. Retrieved from http://bi.galegroup.com.ezp.slu.edu/essentials/article/GALE|A392094536/0feef1e221c a564407c256689dc0eb2f?u=sain44199

Ross, P.E. (2011). When will we have unmanned commercial airliners? Retrieved from http://spectrum.ieee.org/aerospace/aviation/when-will-we-have-unmannedcommercial-airliners/0

Ross, P.J. (1988). Taguchi Techniques for Quality Engineering, McGraw Hill, New York

Sampson, B. (2018). Startup to develop autonomous piloting software for general aviation aircraft, Aerospaseinternationaltesting.com. Retrieved from https://www.aerospacetestinginternational.com/news/software/startup-to-developautonomous-piloting-software-for-small-aircraft.html

Shelton, J. (2018). Will airplanes eventually not need pilots? Quora.com. Retrieved from https://www.quora.com/Will-airplanes-eventually-not-need-pilots

Sigal, S. (2019). Psychology behind self-driving cars, Vox.com. Retrieved from https://www.vox.com/future-perfect/2019/3/20/18273067/self-driving-cars-trumppsychology

Stewart, J. (2014). Pilotless passenger planes prepare for take-off. Retrieved from http://www.bbc.com/future/story/20130502-pilotless-planes-plan-to-take-off

Stickles, B. (2016). Twilight of manned flight? United States Naval Institute Proceedings, 142(4), 24-29. Retrieved from http://argo.library.okstate.edu/login?url=https://searchproquest-com.argo.library.okstate.edu/docview/1780982123 ?accountid=4117

Stouffer, V. (2015). State of the art of autonomous platforms and human-machine systems: only a fool would stand in the way of progress. Presented at 15th AIAA Aviation Technology, Integration and Operations Conference 2015, Dallas, Texas. AIAA.

Straub, J. (2018). Your next pilot could be drone software, CNN.com. Retrieved from https://www.cnn.com/travel/article/pilot-drone-software/index.html

Tam, A. (2011). Public perception of unmanned aerial vehicles. Aviation Technology Graduate Student Publications. Paper 3.http://docs.lib.purdue.edu/atgrads/3

Vance, S.M. (2014). Analysis of factors that may be essential in the decision to fly on fully automated passenger airliners (Order No. 3624132). Available from ABI/INFORM Collection; ProQuest Dissertations \& Theses Global. (1551522384). Retrieved from 
http://argo.library.okstate.edu/login?url=https://search-proquestcom.argo.library.okstate.edu/docview/1551522384?accountid $=4117$

Vance, S.M., Malik, A.S. (2015). Analysis of factors that may be essential in the decision to fly on fully autonomous passenger airliners, Journal of Advanced Transportation, 49(7), 829854., November. doi: 10.1002/atr.1308

Vartabedian, R., Masunaga, S. (2018). Lion air crash shows cockpit computers are no substitute for pilot skills, LA Times. Retrieved from https://www.latimes.com/business/la-fi-lionair-crash-20190204-story.html

Wallander, L. (2009). 25 years of factorial surveys in sociology: A review, Social Science Research, 38505-520. doi:10.1016/j.ssresearch.2009.03.004

Wheatley, S.B. (2006). Unmanned aircraft systems (UAS) and innovation (Order No. MR19079), Pro Quest Dissertations \& Theses A\&I. (305357287). Retrieved from http://search.proquest.com/docview/305357287?accountid=9920

Witcher, Z. (2018). Are you ready to fly without a human pilot? NY Times. Retrieved from https://www.nytimes.com/2018/07/16/business/airplanes-unmanned-flightautopilot.html 